\title{
Glycine Release from Radial Cells Modulates the Spontaneous Activity and Its Propagation during Early Spinal Cord Development
}

\author{
Anne-Laure Scain, ${ }^{1,2,3,4 \star}$ Hervé Le Corronc, $, 1,2,3 \star 4 \star$ Anne-Emilie Allain, ${ }^{5 \star}$ Emilie Muller, ${ }^{1}$ Jean-Michel Rigo, ${ }^{6}$ \\ Pierre Meyrand, ${ }^{5}$ Pascal Branchereau, ${ }^{5 *}$ and Pascal Legendre ${ }^{1,2,3,4 *}$ \\ ${ }^{1}$ Centre National de la Recherche Scientifique (CNRS), Unité Mixte de Recherche (UMR) 7102, Université Pierre et Marie Curie, ${ }^{2}$ Institut National de la \\ Santé et de la Recherche Médicale, Unité 952, Université Pierre et Marie Curie, ${ }^{3} \mathrm{CNRS}$, UMR 7224, Université Pierre et Marie Curie, and ${ }^{4}$ Université Pierre et \\ Marie Curie, Université Paris 06, F-75005 Paris, France, ${ }^{5}$ Université de Bordeaux, CNRS, Centre de Neurosciences Intégratives et Cognitives, UMR 5228, \\ F-33405 Talence, France, and ${ }^{\circ}$ Hasselt University, Biomedical Research Institute/Medical Basic Sciences, Cell Physiology, B-3590 Diepenbeek, Belgium
}

\begin{abstract}
Rhythmic electrical activity is a hallmark of the developing embryonic CNS and is required for proper development in addition to genetic programs. Neurotransmitter release contributes to the genesis of this activity. In the mouse spinal cord, this rhythmic activity occurs after embryonic day 11.5 (E11.5) as waves spreading along the entire cord. At E12.5, blocking glycine receptors alters the propagation of the rhythmic activity, but the cellular source of the glycine receptor agonist, the release mechanisms, and its function remain obscure. At this early stage, the presence of synaptic activity even remains unexplored. Using isolated embryonic spinal cord preparations and whole-cell patch-clamp recordings of identified motoneurons, we find that the first synaptic activity develops at E12.5 and is mainly GABAergic. Using a multiple approach including direct measurement of neurotransmitter release (i.e., outside-out sniffer technique), we also show that, between E12.5 and E14.5, the main source of glycine in the embryonic spinal cord is radial cell progenitors, also known to be involved in neuronal migration. We then demonstrate that radial cells can release glycine during synaptogenesis. This spontaneous non-neuronal glycine release can also be evoked by mechanical stimuli and occurs through volume-sensitive chloride channels. Finally, we find that basal glycine release upregulates the propagating spontaneous rhythmic activity by depolarizing immature neurons and by increasing membrane potential fluctuations. Our data raise the question of a new role of radial cells as secretory cells involved in the modulation of the spontaneous electrical activity of embryonic neuronal networks.
\end{abstract}

\section{Introduction}

A remarkable feature of the developing CNS is its ability to generate spontaneous electrical activity (O’Donovan, 1999; Ben-Ari, 2001; Zhang and Poo, 2001). This activity consists of explosive bursts of action potentials separated by long silences that can spread between brain regions. Such spontaneous activity is thought to be initiated by nonsynaptic transmitter release during early devel-

\footnotetext{
Received May 5, 2009; revised Nov. 8, 2009; accepted Nov. 12, 2009.

This work was supported by Association Française contre les Myopathies (France), Fondation pour la Recherche sur le Cerveau (France), and Conseil Régional d'Aquitaine Grant 20040301202A. A.-L.S. was supported by Fondation pour la Recherche Médicale (France). We thank Drs. Joseph O'Neill and Alain Marty for critical reading of this manuscript.

*A.-L.S., H.L.C., A.-E.A., P.B., and P.L. contributed equally to this work.

Correspondence should be addressed to either of the following: Dr. Pascal Legendre, Inserm Unité 952/Centre National de la Recherche Scientifique, Unité Mixte de Recherche 7224, Université Pierre et Marie Curie, Bâtiment B, étage 6, boite postale 37,7 quai Saint Bernard, F-75005 Paris, France, E-mail: pascal.legendre@snv.jussieu.fr; or Dr. Pascal Branchereau, Centre de Neurosciences Intégratives et Cognitives, Université de Bordeaux et Centre National de la Recherche Scientifique, Unité Mixte de Recherche 5228, Bâtiment B2 Est, étage 4, F-33405 Talence Cedex, France, E-mail: p.branchereau@cnic.u-bordeaux1.fr.

A.-L. Scain, H. Le Corronc, and P. Legendre's present address: Inserm Unité 952, Université Pierre et Marie Curie, Batiment B, etage 6, boite postale 37, 7 quai Saint Bernard, F-75005 Paris, France.

E. Muller's present address: Inserm Unité 766, Faculté de Medecine, 28 Place Henri Dunant, F-63001 Clermont Ferrand Cedex 1, France.

D0I:10.1523/JNEUROSCI.2115-09.2010

Copyright $\odot 2010$ the authors $\quad 0270-6474 / 10 / 300390-14 \$ 15.00 / 0$
}

opment and then synaptically at later stages (O'Donovan, 1999; Ben-Ari et al., 2004). Although the mechanisms of synaptically driven spontaneous activity have yet to be elucidated, it is clear that many excitatory neurotransmitters are involved in the genesis of these bursts (O'Donovan et al., 1998) and that activitydependent network depression likely allows the periods of quiescence between bursts (Tabak et al., 2001). Spontaneous electrical activity that occurs at early stages of development before and during the formation of synaptic networks is needed for neuronal proliferation, migration, and differentiation (Spitzer, 2006). This nonsynaptic early activity was extensively monitored using optical imaging of intracellular $\mathrm{Ca}^{2+}$ and revealed the presence of calcium transients engaging the release of endogenous neurotransmitters and gap junctions ( $\mathrm{Gu}$ and Spitzer, 1997; Spitzer, 2006). However, the identity of the cellular source of these transmitters is less clear: are they released by newly born neurons or by embryonic progenitors cells such as radial cells (RCs), which represent both neuroepithelial cells and radial glial cells in early embryos (Barry and McDermott, 2005)? In the hippocampus, it has been assumed that GABA and glutamate are released by newborn neurons (Demarque et al., 2002). In the developing cortex, taurine, a glycine receptor (GlyR) agonist is thought to be released from immature neurons (Flint et al., 1998). 
In addition, the mechanisms that underlie the nonsynaptic release also remain to be clarified. Paracrine processes operating via unknown pathways are suggested to underlie the liberation of taurine, GABA, and glutamate during early development (Flint et al., 1998; Demarque et al., 2002; Liu et al., 2005; Bordey, 2007).

In the mouse spinal cord (SC), experiments based on extracellular recordings and pharmacology suggest that glycinergic transmission is important to the occurrence of spontaneous rhythmic activities at early stages [as early as embryonic day 12.5 (E12.5)] (Hanson and Landmesser, 2003; Ren and Greer, 2003). However, at this stage, glycinergic interneurons are extremely sparse (Allain et al., 2006), suggesting that GlyR agonists could have a non-neuronal origin. In this study, we investigated the possibility of a nonsynaptic release of glycine at early stages of development in the lumbar SC. Using multiple direct approaches, we demonstrate that RCs release glycine at the onset of synaptogenesis in the SC. We show that glycine release from RCs is independent of action potential firing and is not vesicular. Instead, glycine release is elicited by cell membrane stretch and likely involves volume-sensitive outwardly rectifying (VSOR) chloride channels. We finally demonstrate that this early basal glycine release influences the excitability of SC neurons, thereby modulating the propagation of bursts of action potentials in the isolated embryonic SC.

\section{Materials and Methods}

Isolated spinal cord preparation. These experiments were performed in accordance with European Community guiding principles on the care and use of animals (86/609/CEE; Official Journal of the European Communities no. L358; December 18, 1986), French Decree no. 97/748 of October 19, 1987 (Journal Officiel de la République Française; October 20, 1987) and the recommendations of the Centre National de la Recherche Scientifique. Embryonic SCs from mice were obtained as described previously (Delpy et al., 2008). Briefly, pregnant mice were anesthetized by intramuscular injection of a mix of ketamine and xylazine. Embryos were removed, and the SC was isolated. Whole SCs were then maintained for $1 \mathrm{~h}$ before recording in an artificial CSF (ACSF) containing the following (in mM): $130 \mathrm{NaCl}, 26$ $\mathrm{NaHCO}_{3}, 1.25 \mathrm{NaH}_{2} \mathrm{PO}_{4}, 3 \mathrm{KCl}, 10$ glucose, $2 \mathrm{CaCl}_{2}$, and $2 \mathrm{MgCl}_{2}$, at $32^{\circ} \mathrm{C}$, continuously bubbled with a $95 \% \mathrm{O}_{2}-5 \% \mathrm{CO}_{2}$ gas mixture.

Whole-cell recordings and analysis. The isolated SC was placed in a recording chamber and continuously perfused at room temperature $\left(20-24^{\circ} \mathrm{C}\right)$ with the oxygenated ACSF $(1.9 \mathrm{ml} / \mathrm{min})$. Standard whole-cell voltage-clamp recordings of motoneurons (MNs) were made under direct visualization using an infrared-sensitive CCD video camera. MNs were easily distinguishable by their location in the ventral area and by their size. To confirm motoneuronal identity, the recorded cells were filled with Neurobiotin $(2 \mathrm{mg} / \mathrm{ml})$ and revealed in combination with an Islet $1 / 2$ staining; Islet $1 / 2$ is a specific marker of embryonic MNs (Ericson et al., 1992) (see Fig. 3A,B). Whole-cell patch-clamp electrodes were pulled from thick-wall borosilicate glass using a Brown-Flaming puller (Sutter Instrument). The tip of the electrode was fire-polished using a microforge (Narishige). Patch-clamp electrodes had resistances of 2-4 $\mathrm{M} \Omega$. For voltage-clamp experiments, the electrode was filled with a solution containing the following (in $\mathrm{mm}$ ): $135 \mathrm{CsCl}, 2 \mathrm{MgCl}_{2}, 4$ $\mathrm{Na}_{3}$ ATP, 10 EGTA, and 10 HEPES, pH $7.2\left(290 \mathrm{mosmol} / \mathrm{kg} \mathrm{H}_{2} \mathrm{O}\right)$. For current clamp, the electrode contained the following (in $\mathrm{mM}$ ): 92 K-gluconate, $38 \mathrm{KCl}, 5 \mathrm{NaCl}, 10 \mathrm{HEPES}, 2 \mathrm{MgATP}$, and 1 EGTA, pH 7.4 [ $285 \mathrm{mosmol} / \mathrm{kg} \mathrm{H} \mathrm{H}_{2} \mathrm{O}$; equilibrium potential for chloride ions, $E_{\mathrm{Cl}} \approx-30 \mathrm{mV}$ (i.e., close to the physiological values measured at these embryonic ages) (Delpy et al., 2008)]. Events were recorded using an Axopatch 200B or a Multiclamp 700B amplifier (Molecular Devices). Data were low-pass filtered $(2 \mathrm{kHz})$ and acquired at $10 \mathrm{kHz}$ on a computer using pClamp9 software. Spontaneous events were recorded at a holding potential of $-60 \mathrm{mV}$.

A synaptic current was defined as an event having a fast rise time and a slow decay time. The spontaneous synaptic activity was analyzed during a recording period of 5-10 min. Spontaneous synaptic events were digitized with pClamp9 software (Molecular Devices). Events were detected using a derivative threshold method using Axograph 4.9 (Molecular Devices) and were further accepted or rejected on the basis of their time course (Muller et al., 2006).

Single-channel activity was measured by constructing point-per-point amplitude histograms of successive short data segments (5-10 s) to minimize distortion caused by slow basal current fluctuations (see Fig. 2). The point-per-point amplitude histograms were then averaged. The effects of drugs on single channel activity were analyzed by comparing the averaged point-per-point amplitude histograms obtained from traces of identical duration. The basal current noise peak distribution was fitted using a single Gaussian curve. As shown in Figure 2, single-channel currents have an inward direction. The single-channel current activity was estimated by measuring the area of the point-per-point amplitude histograms for current values lower than 2 times the SD value of the Gaussian curve describing the basal current noise distribution (SD values usually ranged from 0.5 to $1.3 \mathrm{pA}$ between recordings).

Extracellular recordings and stimulations. In the same experimental conditions as for whole-cell recordings, spontaneous activity was recorded extracellularly from E12.5 spinal cords using a glass electrode placed into the ventral cord and connected to a high-gain AC amplifier (ISO-DAM8A-4 Bio-amplifier System; World Precision Instruments). Filtered (bandwidth, $300 \mathrm{~Hz}$ to $10 \mathrm{kHz}$ ) raw signals were integrated offline and analyzed using Spike2 software (Cambridge Electronic Design). Changes in burst area and burst duration were calculated from cervical, thoracic, and lumbar recordings. Data in the present study correspond to mean modifications across the three spinal cord levels. Episodes of activity were induced by electrical stimulations, through a bipolar electrode positioned at cervical level, using a Master-8-vp connected to ISO-Flex isolation units (A.M.P.I.).

Sniffer recordings. To make a "sniffer" electrode (Young and Poo, 1983), an outside-out patch was pulled from a transfected CHO cell line expressing the GlyR $\alpha 2$ subunit (Mangin et al., 2003). Homomeric GlyR $\alpha 2$ subunits, highly specific for glycine, were characterized by a high elementary conductance (100-120 pS), a long mean open time, and little desensitization, making them a good sensor for glycine (Mangin et al., 2003). As a control, the electrode was first positioned outside the SC to verify any glycine contamination in the recording medium. The electrode was then pushed inside the SC and positioned within the motoneuronal area. Outside-out patch-clamp electrodes (5-10 M $\Omega$ ) were pulled from thick-wall borosilicate glass, fire-polished, and filled with the following (in mM): $130 \mathrm{CsCl}, 4 \mathrm{MgCl}_{2}, 4 \mathrm{Na}_{2} \mathrm{ATP}, 10$ EGTA, 10 HEPES, pH 7.2; osmolarity, $290 \mathrm{mosmol} / \mathrm{kg} \mathrm{H}_{2} \mathrm{O}$. Single-channel currents were recorded using an Axopatch 200B amplifier (Molecular Devices). Recordings were filtered at $10 \mathrm{kHz}$, sampled at $50 \mathrm{kHz}$, and stored on a PC computer. Membrane potential was held at $-50 \mathrm{mV}$ throughout the experiment. Analysis of the sniffer currents was performed using Axograph 4.9 software (Molecular Devices). Decay rates of sniffer currents were estimated by measuring the duration of the sniffer current at $20 \%$ of the peak amplitude (see Fig. 7). One thousand consecutive points were averaged to measure changes in current amplitude with time (sampling rate, $50 \mathrm{kHz}$ ).

Chinese hamster ovarian cells (CHO-K1; ATCC CCL61) were maintained in a $95 \%$ air $-5 \% \mathrm{CO}_{2}$ humidified incubator, at $35^{\circ} \mathrm{C}$, in DMEM supplemented with $0.11 \mathrm{~g} / \mathrm{L}$ sodium pyruvate, $6 \mathrm{~g} / \mathrm{L} \mathrm{D-glucose}$, and $10 \%$ $(\mathrm{v} / \mathrm{v})$ heat-inactivated fetal bovine serum (all from Invitrogen). Cells were passaged every 5-6 d (up to a maximum of 20 times). For electrophysiological recordings, cells were seeded onto glass coverslips coated with poly-L-ornithine $(0.1 \mathrm{mg} / \mathrm{ml})$. Glycine receptor $\alpha_{2}$ subunit cloning and transfection were performed as described by Mangin et al. (2003).

Pharmacological agents. All drugs were bath-applied. The glycine receptor antagonist strychnine hemisulfate salt (1-5 $\mu \mathrm{M}$; Sigma-Aldrich), the $\mathrm{GABA}_{\mathrm{A}}$ receptor antagonist gabazine ( $2 \mu \mathrm{m}$; Sigma-Aldrich), and TTX (0.5-1 $\mu \mathrm{M}$; Sigma-Aldrich) were dissolved in the bathing solution. The glycine membrane transporter 1 (GlyT1) blocker $N$-[3-(4'-fluorophenyl)3-(4'-phenylphenoxy)propyl] sarcosine hydrochloride (ALX-5407) (1 $\mu \mathrm{M}$; Sigma-Aldrich) was dissolved in ACSF. The nonspecific GlyT blocker O-[(2-benzyloxyphenyl-3-flurophenyl)methyl]-L-serine (ALX- 
Table 1. Primary antibodies used in the present study (all with a $2 \%$ PFA fixation)

\begin{tabular}{llll}
\hline Antigen & Type & Name & Origin \\
\hline Glycine-PFA conjugate & Rat polyclonal & & Gilution \\
Islet1/2 & Mouse monoclonal & $40.2 \mathrm{D} 639.4 \mathrm{D} 5$ & Developmental Studies Hybridoma Bank \\
Nestin & Mouse monoclonal & Rat 401 & Developmental Studies Hybridoma Bank \\
RC2 & Mouse monoclonal & RC2 & Developmental Studies Hybridoma Bank \\
Taurine-PFA conjugate & Rabbit polyclonal & IG1109 & ImmunoSolution PTY \\
VIAAT & Rabbit polyclonal & & Gift from Dr. B. Gasnier (Institut de Biologie Physico-Chimique, Paris, France) \\
\hline
\end{tabular}

1393) (0.5 $\mu \mathrm{M}$; Sigma-Aldrich), flufenamic acid (100 $\mu \mathrm{M}$; Sigma-Aldrich), 4-(2-butyl-6,7-dichloro-2-cyclopentylindan-1-on-5-yl)oxybutyric acid

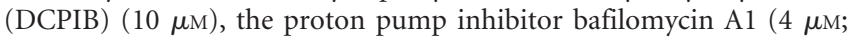
Tocris), and capsaicin (10 $\mu \mathrm{M}$; Sigma-Aldrich) were dissolved in DMSO (final concentration, 0.1\%). 1-[2-(4-Methoxyphenyl)-2-[3-(4-methoxyphenyl)propoxy] ethyl]-1 $\mathrm{H}$-imidazole hydrochloride (SKF-96365) (30-100 $\mu \mathrm{M}$; Tocris), gadolinium $\left(\mathrm{GdCl}_{3}\right)(100 \mu \mathrm{M}$; Sigma-Aldrich), adenosine triphosphate (ATP-Na) (20 $\mu$; Sigma-Aldrich), DCPIB (10 $\mu \mathrm{M}$; Tocris), and phloretin (10 $\mu \mathrm{M}$; Sigma-Aldrich) were dissolved in ACSF. ATP-Na was first solubilized in sterile cold water to obtain $20 \mathrm{~mm}$ and then diluted to $20 \mu \mathrm{m}$ in ACSF before use. Capsaicin (Tocris) was first solubilized in DMSO (Sigma-Aldrich) to obtain $10 \mathrm{~mm}$, and then diluted to $10 \mu \mathrm{M}$ in ACSF (0.1\% DMSO final concentration).

SCs were incubated for $1-3 \mathrm{~h}$ in the presence of bafilomycin A1 before recordings. ACSF containing $0.1 \%$ DMSO did not affect synaptic activity or GlyR activation (data not shown).

Immunohistochemistry. Immunostaining was performed on SC transverse lumbar sections. For sectioning, E11.5-E15.5 SCs were fixed in 2\% paraformaldehyde (PFA) for $2 \mathrm{~h}$, rinsed in $0.1 \mathrm{M}$ PBS, cryoprotected in sucrose, frozen, and transversally cut in $25-\mu \mathrm{m}$-thick sections using a Leica CM $3050 \mathrm{~S}$ cryostat. For hypotonic tests, E12.5 SCs were incubated for $1 \mathrm{~h}$ either in control conditions ( $325 \mathrm{mosmol} / \mathrm{kg} \mathrm{H}_{2} \mathrm{O}$ ACSF) or in hypotonic ACSF ( $200 \mathrm{mosmol} / \mathrm{kg} \mathrm{H}_{2} \mathrm{O}$ ) with or without specific drugs (see Results) before fixation. For taurine immunostaining, cerebella were collected from adult mice perfused with $2 \%$ PFA. Sections were incubated with primary antibodies for $48 \mathrm{~h}$ at $4^{\circ} \mathrm{C}$ in $0.1 \mathrm{M}$ PBS (containing $0.2 \%$ BSA and $0.1 \%$ Triton X-100). All primary antibodies used are listed in Table 1. To reveal Neurobiotin-injected MNs, streptavidin-Cy5 (1: 400; Invitrogen) was added to the primary antibody solution. Then, after three rinses in PBS, SCs were incubated at room temperature for $2 \mathrm{~h}$ in appropriate secondary antibodies (1:400; Invitrogen). These were Alexa Fluor 488 goat anti-rabbit or anti-mouse $\operatorname{IgG}(\mathrm{H}+\mathrm{L})$, Alexa Fluor 546 goat anti-mouse $\operatorname{IgG}(\mathrm{H}+\mathrm{L})$ or donkey anti-rat $\operatorname{IgG}(\mathrm{H}+\mathrm{L})$. After rinsing in $0.1 \mathrm{M}$ PBS, SCs were mounted in $90 \%$ glycerol $/ 10 \% \mathrm{PBS} / 2.5 \%$ DABCO [1,4-diazabicyclo(2.2.2)octane] (Sigma-Aldrich). Even though the specificity of the polyclonal rat anti-glycine antibody was verified using immunoblotting by Prof. D. Pow (University of Newcastle, Newcastle, Australia) (Pow et al., 1995), the specificity of the glycine labeling was tested using a glycine-PFA-BSA conjugate as previously referred to (Allain et al., 2006).

Confocal microscopy. Preparations were analyzed using a BX51 Olympus Fluoview 500 confocal microscope. For quantitative analysis of labeled RC fibers on SC transverse sections, serial optical sections were obtained at a $Z$-step of $0.3 \mu \mathrm{m}$ and imaged using an objective $40 \times / 1.00$ numerical aperture oil.

Image analysis, quantification, and statistics. In transverse sections of embryonic lumbar SCs, nestin-immunoreactive (ir), glycine-ir, and double-stained nestin/glycine RC fibers were counted manually in three optical sections (5-11 embryos, three different litters) randomly chosen in the ventral area. The threshold used to determine whether a cell was coimmunolabeled was set at twice the intensity of background noise measured between radial cell fibers. Background noise intensity did not strongly vary between experiments. All values were expressed as mean \pm SEM. Statistical significance was assessed by a one-way ANOVA or by nonparametric Mann-Whitney test or Wilcoxon's matched pairs test (GraphPad Software).

Lucifer yellow and Neurobiotin uptake. For Lucifer yellow (LY) uptake experiments, embryonic SCs (E12.5-E13.5) were isolated with meninges in ACSF (30 min). SCs were then transferred into chambers containing 1 mM LY (Sigma-Aldrich) dissolved in ACSF. To determine whether isotonic solutions can increase LY uptake by RCs, SCs were exposed for $15-20 \mathrm{~min}$ to $\mathrm{LY}$ dissolved in $200 \mathrm{mosmol} / \mathrm{kg} \mathrm{H}_{2} \mathrm{O}$ solution. For Neurobiotin uptake experiments, SCs were prepared as described above but LY was replaced with $3.5 \mathrm{~mm}$ Neurobiotin (Vector Laboratories). All experiments were performed at $32^{\circ} \mathrm{C}$. SCs were fixed overnight in $4 \%$ PFA and cryoprotected for $24 \mathrm{~h}$ in sucrose. Transverse frozen sections $(35 \mu \mathrm{m}$ thick) were made, rinsed in $0.1 \mathrm{M}$ PBS, and mounted with Vectashield (Vector Laboratories). For Neurobiotin staining, cryostat slices were rinsed in PBS and quenched in $50 \mathrm{mM} \mathrm{NH}_{4} \mathrm{Cl}$ in $\mathrm{PBS}$ for $20 \mathrm{~min}$ at room temperature. To reveal Neurobiotin-labeled cells, slices were permeabilized in $0.2 \%(\mathrm{v} / \mathrm{v})$ Triton X-100 (Sigma-Aldrich) and 0.25\% (v/v) fish gelatin (Sigma-Aldrich) for $1 \mathrm{~h}$ at room temperature. They were then incubated for $3 \mathrm{~h}$ at room temperature with streptavidin-Alexa 488 (1: 500) (Invitrogen). Slices were then rinsed in PBS before being mounted with Vectashield. Fluorescence was observed under a confocal laserscanning microscope (Leica SP5) using a $40 \times$ oil-immersion objective of numerical aperture 1.25. The dyes LY and Alexa 488 were excited with a $405 \mathrm{~nm}$ diode laser and the $488 \mathrm{~nm}$ line of an argon laser, respectively. The $x-y$ resolution of each stack was $2048 \times 2048$ pixels over a scan area of $387.5 \times 387.5 \mu \mathrm{m}^{2}$. Typically, stacks of 30 sections with an interval of $0.5 \mu \mathrm{m}$ from the surface were scanned three times to optimize the signalto-noise ratio. ImageJ public domain software (Wayne Rasband; National Institutes of Health; http://rsb.info.nih.gov/ij/) was used to analyze projections from stack sections. The threshold used to determine whether a cell took up Lucifer yellow or Neurobiotin was set at twice the intensity of background noise measured outside the ventromedial part of the spinal cord (background noise intensity did not strongly vary between experiments). Because somata of RCs are located in the intermediate part of the ventricular zone, the number of stained RCs was estimated by counting fluorescent cell bodies in the ventral part of the ventricular zone (within a $300 \mu \mathrm{m}$ area dorsal to the floorplate).

\section{Results}

\section{Spontaneously active GlyRs at E12.5 in the embryonic spinal cord}

Direct evidence concerning the establishment of GABAergic and glycinergic synaptic transmission in embryonic spinal motor networks has not yet been reported. Using whole-cell patch-clamp recordings from visually identified lumbar E11.5-E14.5 spinal MNs (Fig. $1 B$ ), we first analyzed the ontogeny of isolated spontaneous postsynaptic activity. Postsynaptic currents (PSCs) were defined in a classical way, as events with a fast rising phase and a slow decay phase. At these ages, $\mathrm{MN}$ input resistance remained $>600 \mathrm{M} \Omega$, whereas their input capacitance increased from $11.8 \pm 5.0 \mathrm{pF}(n=10)$ at $\mathrm{E} 11.5$ to $19.8 \pm 1.8 \mathrm{pF}(n=21)$ at $\mathrm{E} 14.5$, as previously described (Delpy et al., 2008).

At E11.5, we observed no spontaneous synaptic activity on the 10 recorded MNs (data not shown). At E12.5, spontaneous isolated PSCs were either still not detected or occurred at a low frequency ranging from 0.004 to $0.03 \mathrm{~Hz}$. Application of $30 \mathrm{~mm}$ $\mathrm{KCl}$ did not increase synaptic activity (data not shown). Only $13.3 \%$ of MNs $(n=30)$ displayed PSCs with a frequency $>0.05$ $\mathrm{Hz}$, ranging from 0.1 to $0.45 \mathrm{~Hz}(0.21 \pm 0.07 \mathrm{~Hz} ; n=4)$ (Fig. $1 A-D 1)$. The proportion of recorded cells displaying PSCs with a 

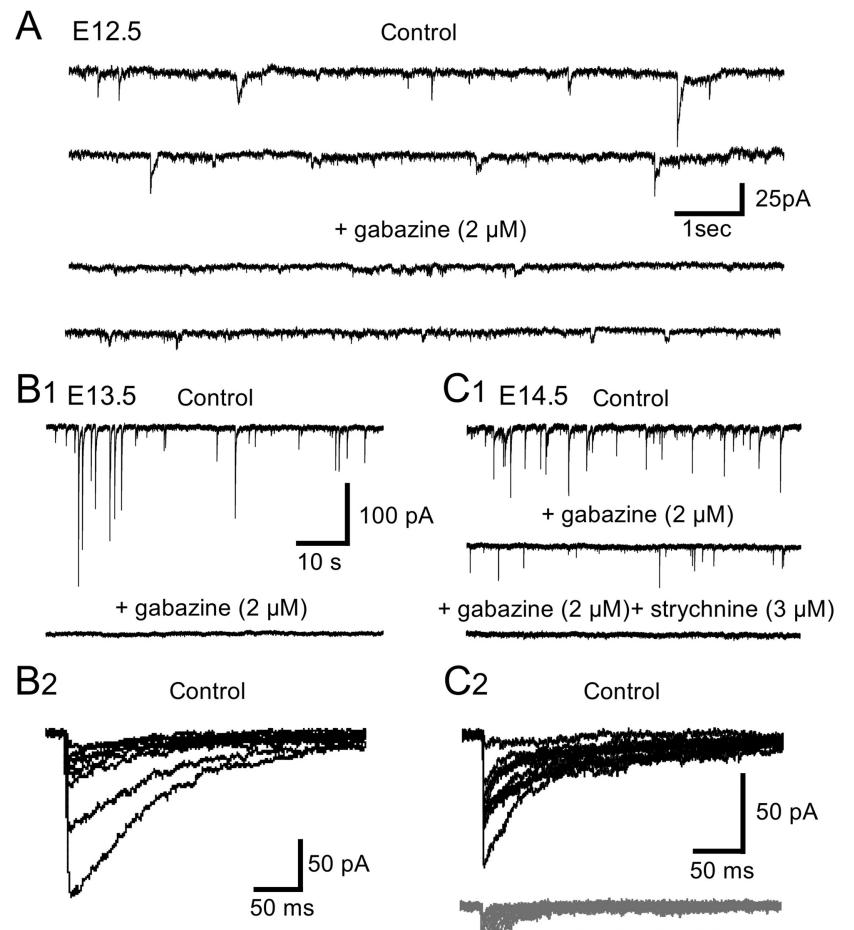

C2 Control
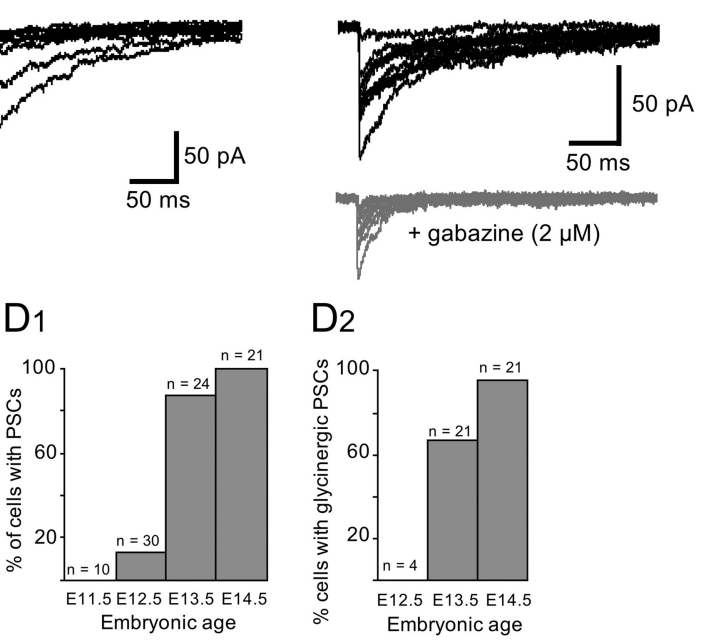

Figure 1. Spontaneous activity recorded in MNs from E12.5 to E14.5. A, Example of spontaneous activity recorded from an E12.5 MN. Application of $2 \mu \mathrm{m}$ gabazine blocked postsynapticlike events (bottom traces), whereas small events were not affected. $\boldsymbol{B}, \boldsymbol{C}$, Example of postsynaptic activity recorded at E13.5 and E14.5. B1, In a representative MN, gabazine application $(2 \mu \mathrm{M})$ completely suppressed PSCS, indicating that they are mainly GABAergic. B2, Superimposed traces of gabazine-sensitive PSCS (same MN as in $\boldsymbol{B} 1 ; n=10$ ). $\mathbf{C}$, In another representative MN (E14.5), gabazine did not completely inhibit spontaneous postsynaptic activity. These gabazine-resistant PSCs were completely blocked by strychnine (3 $\mu \mathrm{m}$; bottom trace), indicating that they were glycinergic. C2, Superimposed PSCs recorded in control conditions (top trace; $n=10$ ) or in the presence of gabazine ( $3 \mu \mathrm{m}$; bottom trace; $n=10)$. D1, Proportion of MNs with PSC frequency $>0.05 \mathrm{~Hz}$ at E11.5-E14.5. D2, Glycinergic PSCs were first detected at E13.5 and the proportion of cells displaying glycinergic PSCs increased at E14.5.

frequency $>0.05 \mathrm{~Hz}$ increased to $90.5 \%(n=24)$ at E13.5 and $100 \%(n=21)$ at E14.5 (Fig. 1 D1). At E13.5, the most active cells displayed PSCs with an averaged frequency of $0.22 \pm 0.04 \mathrm{~Hz}$ $(n=21)$, whereas the three poorly active cells displayed PSCs with a frequency ranging from 0.005 to $0.02 \mathrm{~Hz}$. At E14.5, PSC frequency significantly increased to $0.39 \pm 0.08 \mathrm{~Hz}(n=21)$ when compared with the most active cells recorded at E13.5 (Mann-Whitney test, $p=0.05$ ).

At E12.5, all PSCs were blocked by the $\mathrm{GABA}_{\mathrm{A}} \mathrm{R}$-specific antagonist gabazine $(2 \mu \mathrm{M})$, indicating that these synaptic currents were GABAergic postsynaptic events (Fig. 1A). At E13.5, gabazine abolished PSCs in 33.3\% of the recorded MNs (Fig. 1B1), whereas other MNs expressed a proportion of gabazine-resistant PSCs that were fully blocked by strychnine, thus suggesting the
A

Control
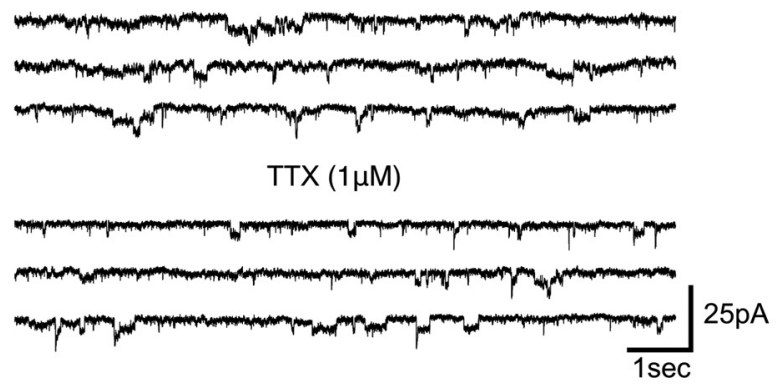

B

Control

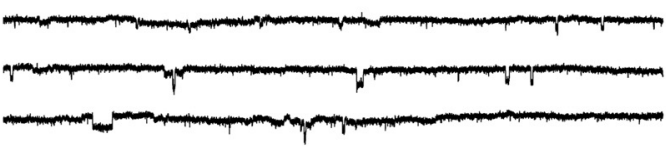

Gabazine $(2 \mu \mathrm{M})$

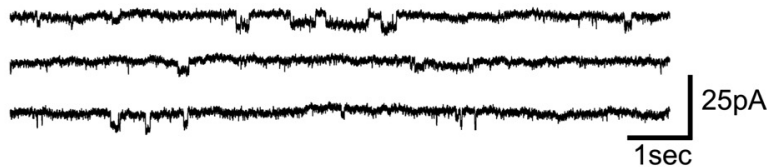

$\mathrm{C}_{1}$

Control

Strychnine $(3 \mu \mathrm{M})$
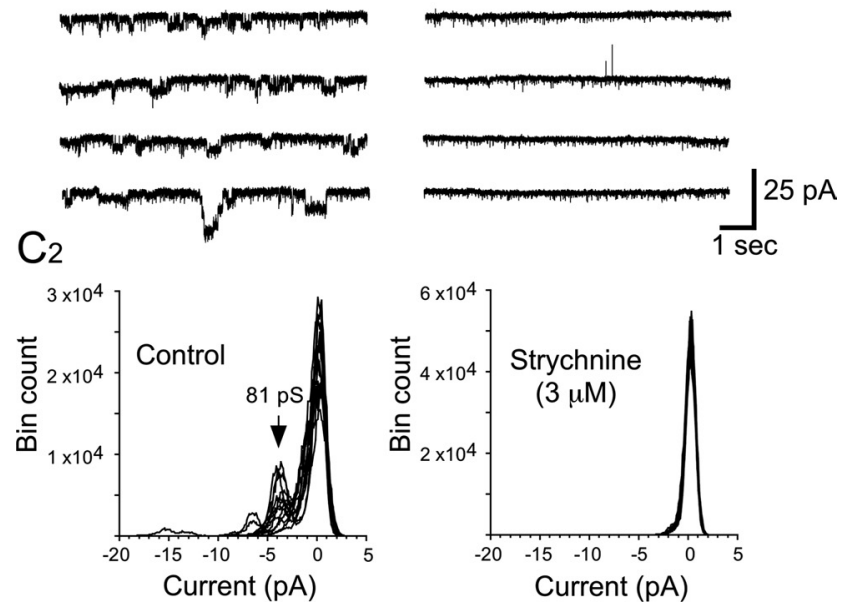

Figure 2. Spontaneous single-channel activity recorded in E12.5 lumbar MNs. A, Spontaneous single-channel currents obtained in patch-clamp whole-cell recordings were insensitive to $1 \mu \mathrm{M}$ TTX. B, Spontaneous activity was not prevented by gabazine application, indicating that it does not only represent openings of $G A B A_{A}$ receptors. $(1$, Conversely, an application of strychnine inhibited this activity, revealing GlyR activation. (2, Superimposed point-per-point amplitude histograms of channel openings obtained before (left) and during (right) strychnine application. Each histogram was built from 12 consecutive 10 s epochs.

presence of GABAergic or glycinergic events, or both (Fig. 1D2). At E14.5, 90.5\% of the cells displayed GABAergic and glycinergic PSCs (Fig. 1C1-D2). When present, glycinergic PSCs did not appear more frequently in E14.5 compared with E13.5 MNs. There was no significant difference (Mann-Whitney test, $p>$ $0.1)$ in the proportion of gabazine-resistant PSCs between E13.5 $(14.6 \pm 3 \% ; n=14)$ and E14.5 $(21.9 \pm 4.2 \% ; n=19)$.

Whole-cell recordings also revealed spontaneously occurring single-channel currents, which were more pronounced at E12.5 (Fig. 2A), and appeared well defined ( $4-5 \mathrm{pA}$ at $-60 \mathrm{mV}$ ) because of the high input resistance of MNs $(722 \pm 37 \mathrm{M} \Omega ; n=30$ at E12.5). Single-channel activity was characterized by inward currents with a square time course (Fig. 2). The single-channel 
activity was quantified using point-perpoint current amplitude histograms (see Materials and Methods). This singlechannel current activity was not significantly decreased (Wilcoxon's test, $p>$ $0.1)$ by $1 \mu \mathrm{M}$ TTX $(3.6 \pm 6.2 \%$ decrease; $n=6$ ) (Fig. $2 A$ ) (i.e., they did not depend on TTX-sensitive action potential firing). They were not significantly inhibited (Wilcoxon's test, $p>0.1$ ) by $2 \mu \mathrm{M}$ gabazine $(2.9 \pm 14.2 \%$ decrease; $n=5$ cells $)$ (Fig. $2 B$ ) but were significantly inhibited (Wilcoxon's test, $p<0.01$ ) by $1-3 \mu \mathrm{M}$ strychnine $(83.8 \pm 3.5 \%$ decrease; $n=9$ cells) (Fig. 2C), indicating that they reflect spontaneous GlyR activation.

The strychnine-sensitive and TTXinsensitive single-channel activity suggests that GlyRs expressed by E12.5 MNs are continuously activated by the presence of endogenous agonist in the extracellular space. We therefore tested whether this tonic activity influenced the resting membrane potential of E12.5 MNs. MNs were recorded in current-clamp mode with the equilibrium chloride potential set at physiological value for this age $\left(E_{\mathrm{Cl}-}=-30\right.$ $\mathrm{mV}$ ), as previously described (Delpy et al., 2008). Bath application of strychnine (5 $\mu \mathrm{M})$ hyperpolarized the membrane potential of all tested MNs $(4.4 \pm 0.6 \mathrm{mV}$; $n=9)$, and in six of them, there was a $39.4 \pm 5 \%$ decrease in the membrane noise fluctuation (Wilcoxon's matched test, $p<0.01$ ) (supplemental Fig. 1, available at www.jneurosci.org as supplemental material) [change in the membrane noise fluctuation was estimated by calculating the coefficient of variation $(\mathrm{CV})$ of the noise $(\mathrm{CV}=\mathrm{SD} /$ mean $)]$. This indicates that spontaneous GlyR activity can sustain a significant depolarization of the MNs.

\section{Radial cell fibers contain glycine}

Glycine-ir neurons are sparse in the ventral part of the mouse lumbar SC at E12.5 (Allain et al., 2006), arguing against a glycine release from interneurons. At this age, glycine-ir fibers radiate to the border of the ventral horn (Allain et al., 2006) across Islet 1/2-ir motoneuronal pools (Fig. 3A). Since this morphology resembles RCs, we determined whether glycine-ir fibers are from RCs by performing double immunolabeling against glycine and nestin or against glycine and RC2. Nestin and RC2 are intermediate filament proteins expressed in RCs including neuroepithelial and radial glial cells (Hartfuss et al., 2001). We found that glycine-ir fibers were stained with anti-nestin (Fig. 3C) and anti-RC2 antibodies (Fig. $3 D$ ), indicating that they are RC fibers. Double labelings performed from E11.5 to E15.5 also revealed that RC fibers briefly express glycine immunoreactivity, the proportion of glycine-ir RCs being maximal at E13.5 (79.1 $\pm 3.8 \% ; n=18)$ (Fig. $3 E)$. After
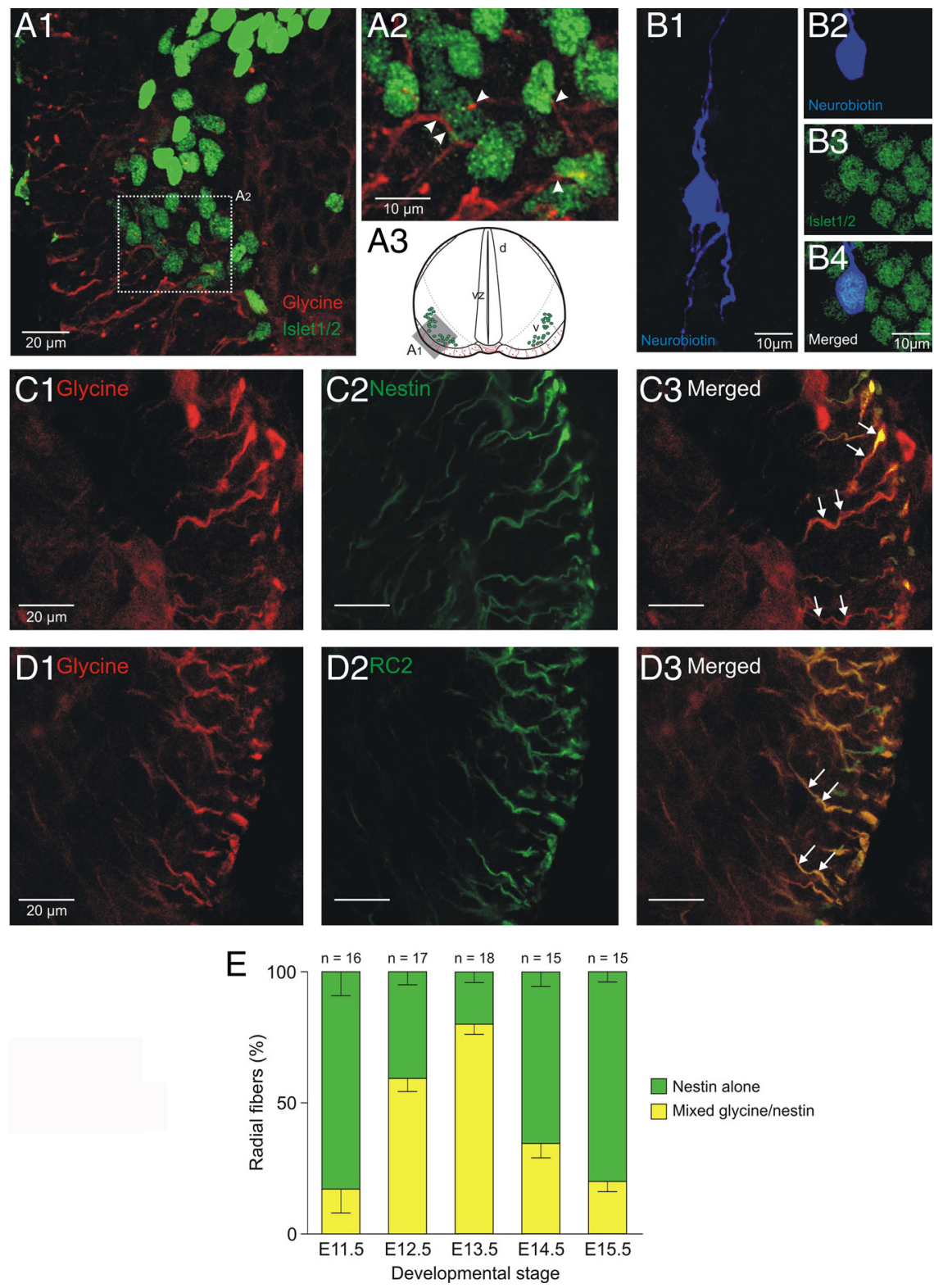

Figure 3. Radial cells contain glycine in the mouse lumbar embryonic spinal cord. $\boldsymbol{A 1}$, Double glycine (red) and Islet1/2 (green) immunostaining at E12.5. A2, Note that glycine-ir fibers (red) invade the motoneuronal area surrounding Islet1/2-ir MNs (arrowheads). A3, Scheme of the sagittal slice in $\boldsymbol{A}$ 1 showing the location of Islet1/2-ir MNs (green). d, Dorsal; v, ventral; vz, ventricular zone. B1, Confocal image of an E12.5 neuron, located in the $\mathrm{MN}$ area, recorded and filled with Neurobiotin. The image represents a stack of 91 confocal optical sections ( $0.3 \mu \mathrm{m}$ thick each). B2-B4, Example of a neuron filled with Neurobiotin and immunostained with the MN marker Islet1/2. C, Double glycine (C1; red) and nestin (C2; green) immunostaining at E12.5. D, Double glycine (D1; red) and RC2 (D2; green) labeling at E12.5. C3, D3, Nestin-ir and RC2-ir fibers (arrows) contain glycine. $E$, Changes in the percentage of RCs expressing glycine between E11.5 and E15.5. The percentage of RCs expressing glycine (yellow) is maximal at E13.5. Above the bars are shown the number of SC sections analyzed. Error bars indicate SEM. C, D, Each image corresponds to a single $0.3-\mu \mathrm{m}$-thick confocal section.

E15.5, nestin immunoreactivity disappeared (data not shown), as already described in the rat SC (Barry and McDermott, 2005).

Taurine is another GlyR agonist known to be released before synaptogenesis in the neonatal rat cortex (Flint et al., 1998). Therefore, taurine could also be an endogenous GlyR agonist in the embryonic mouse SC. To determine whether taurine was also present in E12.5 lumbar SC, we performed a double immunolabeling using anti-taurine and anti-nestin antibodies. Taurine was only detected in the lateral border of the marginal zone in E12.5 lumbar SC sections (supplemental Fig. 2 B, available at www.jneurosci.org as supplemental material). We did not 
detect taurine staining either in the ventral motor area or in the RCs (supplemental Fig. 2 B3, available at www.jneurosci.org as supplemental material), which makes it unlikely that taurine could account for activation of GlyR on MNs.

\section{Glycine is released in response to cell membrane stretch}

Detecting glycine immunoreactivity within RC fibers does not necessarily imply that glycine is released by RCs. To demonstrate glycine release, we first used outside-out patches from $\mathrm{CHO}$ cells expressing embryonic homomeric $\alpha 2$ GlyRs as a "sniffer" (supplemental Fig. 3, available at www.jneurosci.org as supplemental material) to reveal the presence of glycine in the extracellular space within the $\mathrm{MN}$ area. Glycine $\mathrm{EC}_{50}$ is close to $200 \mu \mathrm{M}$ for homomeric $\alpha 2$ GlyRs (Mangin et al., 2003). Note that homomeric $\alpha 2$ GlyRs are poorly sensitive to taurine with a taurine $\mathrm{EC}_{50}$ being 10 times higher than the glycine $\mathrm{EC}_{50}$ (De Saint Jan et al., 2001).

When inserting the sniffer electrode in the vicinity of MNs, we recorded outside-out currents (supplemental Fig. $3 B$, available at www.jneurosci.org as supplemental material). These currents were characterized by an initial peak followed by a deactivation phase (Fig. 4A1, A2) that did not result from GlyR desensitization (Fig. 4). Before E14.5, GlyR activity was still observed 15 min after inserting the sniffer electrode (Fig. 4A1). We estimated the peak concentration of glycine around MNs to be $100 \mu \mathrm{M}$ at E11.5E13.5 (Fig. 4B1-B3) and $30 \mu \mathrm{M}$ at E14.5 (Fig. 4B4). We found that the glycine concentration accounting for GlyR activity 15 min after the sniffer electrode insertion was low $(<10 \mu \mathrm{M})$ but sufficient to activate GlyR between E11.5 and E13.5 (Fig. 4C). It was maximal at E13.5 and, hence, likely to reflect basal extracellular glycine concentration accounting for the spontaneous GlyR activity recorded in motoneurons (Fig. 2). We did not detect any GlyR activity 15 min after the sniffer electrode insertion at E14.5, thus indicating that glycine concentration is below the detection threshold of the sniffer patch (Fig. 4C).

The possibility of evoking glycine release, and hence GlyR activation, by inducing a global cell membrane depolarization, was tested using bath application of $30 \mathrm{~mm} \mathrm{KCl}$. Increasing $\left[\mathrm{K}^{+}\right]_{\mathrm{o}}$ at E12.5-E14.5 did not evoke any significant GlyR activation in the sniffer patch (Fig. $5 A, E$ ). Thus, glycine cannot be released (or is released at a concentration too low to be detected by the sniffer) in response to cell membrane depolarization.

Because nonsynaptic release of neurotransmitters can also be evoked by cell membrane stretches (Chavas et al., 2004), we tested the effect of applying a hypotonic solution to our preparation. Lowering the external osmotic pressure is known to evoke swelling, which in turn increases the mechanical tension of cell membranes. A medium osmolarity of $200 \mathrm{mosmol} / \mathrm{kg} \mathrm{H}_{2} \mathrm{O}$ was chosen according to what is known for mechanical release of ATP by astrocytes (Liu et al., 2008). As shown in Figure 5B, a large inward current, reflecting a release of glycine, was reproducibly induced when reducing extracellular osmotic pressure from 325 to $200 \mathrm{mosmol} / \mathrm{kg} \mathrm{H}_{2} \mathrm{O}$ (i.e., $40 \%$ reduction). This glycine release was observed at all stages tested (E11.5-E14.5) and was reversed when the osmotic pressure was restored to control value (325 $\mathrm{mosmol} / \mathrm{kg} \mathrm{H}_{2} \mathrm{O}$ ) (Fig. $5 \mathrm{~B}$ ). Since reducing the osmolarity also decreases $\left[\mathrm{Na}^{+}\right]_{\mathrm{o}}$ and $\left[\mathrm{Cl}^{-}\right]_{\mathrm{o}}$, we determined whether a GlyR activation in the sniffer patch could still be observed when the osmotic pressure is restored using glycerol. Glycerol had no noticeable effect on GlyR intrinsic activation properties (data not shown). Restoring the osmotic pressure with a glycerol solution suppressed outside-out current, whereas an additional hypotonic challenge reactivated GlyRs in the sniffer patch $(n=4)$ (Fig. $5 C)$,
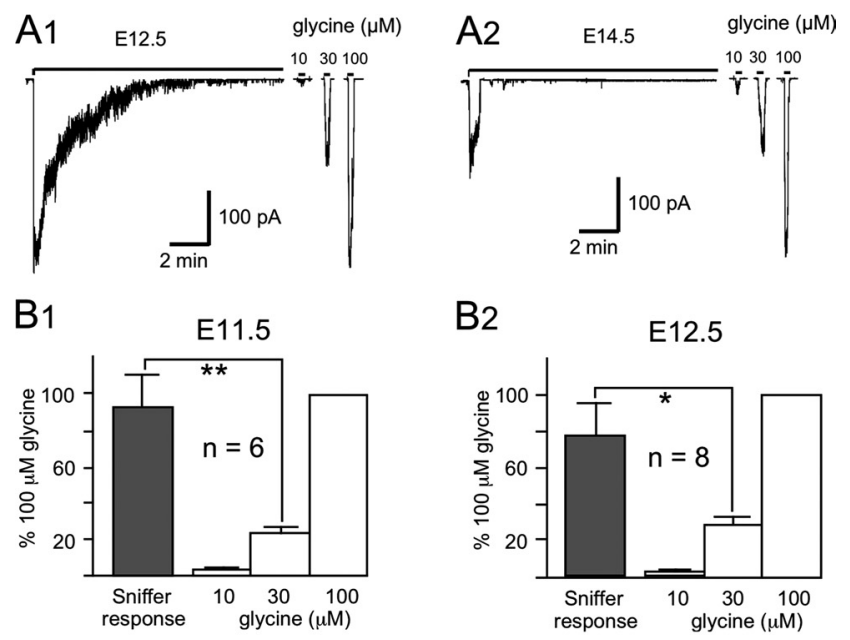

B2
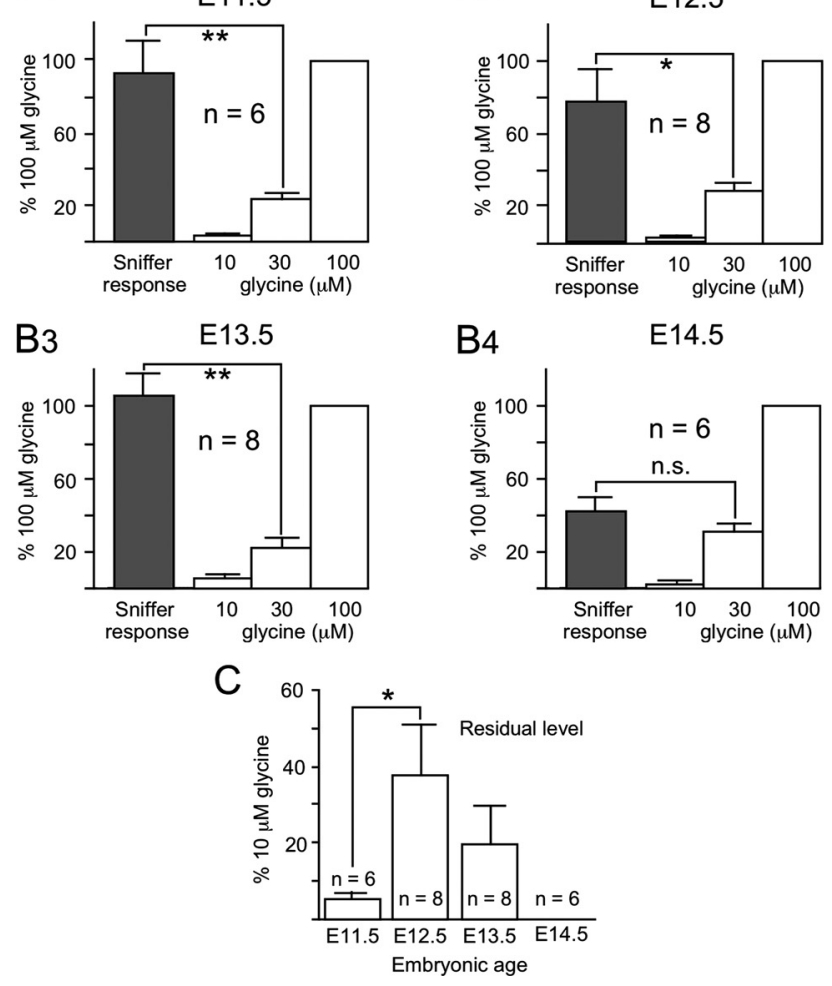

Figure 4. Estimation of the endogenous [glycine $]_{0}$ within the motoneuronal area using the sniffer technique. $\boldsymbol{A}$, Left-hand traces, Examples of GlyR activity recorded from a sniffer positioned (horizontal line) within the lumbar motoneuronal area at E12.5 (A1) and at E14.5 (A2). A1, Note that, at E12.5, GlyRs remained activated 15 min after positioning the electrode within the SC. The right-hand panels in $\boldsymbol{A} \mathbf{1}$ and $\boldsymbol{A} \mathbf{2}$ correspond to sniffer responses evoked by exogenous application of 10,30 , and $100 \mu \mathrm{m}$ glycine onto the same outside-out patch illustrated on the left panels. Glycine was applied after pulling the sniffer electrode out of the SC. $\boldsymbol{B}$, Estimation of the [glycine] detected by the sniffer patch at E11.5 (B1), E12.5 (B2), E13.5 (B3), and E14.5 (B4). To compare sniffer responses observed after positioning the electrode within the $\mathrm{SC}$ with responses evoked by different exogenous applications of glycine, responses were normalized to currents evoked by $100 \mu \mathrm{m}$ glycine. Note that the peak amplitude of the currents obtained within the motoneuronal area (gray bar) at E11.5 (B1), E12.5 (B2), and E13.5 (B3) was significantly different from the amplitude of the current evoked by the application of $\leq 30 \mu \mathrm{m}$ glycine (ANOVA test, ${ }^{*} p<0.05,{ }^{* *} p<0.01$ ). $\boldsymbol{B 4}$, Endogenous [glycine $]_{0^{\prime}}$ estimated at the peak of the sniffer response, was close to $30 \mu \mathrm{m}$ at E14.5. C, The residual concentration level of glycine in the extracellular space was estimated 15 min after positioning the sniffer electrode within the motoneuronal area. The residual sniffer response amplitude was normalized to the outside-out current evoked by $10 \mu \mathrm{m}$ glycine application. Note that the basal concentration of glycine was maximal at E12.5 and E13.5 (Kruskal-Wallis test, ${ }^{*} p<0.05$ ). It was probably between 3 and $10 \mu \mathrm{m}, 3 \mu \mathrm{m}$ glycine being unable to activate homomeric $\alpha 2 \mathrm{GlyRs}$. Note that, at E14.5, the sniffer electrode failed to detect the presence of glycine in the extracellular space. Error bars indicate SEM.

indicating that glycine release is selectively evoked by decreasing the osmotic pressure. To test whether glycine release could be evoked by mechanical stimuli alone, we touched a fired polished electrode on the surface of the SC (club-ending with a 5-10 $\mu \mathrm{m}$ tip) to stimulate the radial cell end feet, as previously described for mechanical stimulation of astrocytic end feet in the hip- 
pocampus (Kozlov et al., 2006). The clubending of the electrode was first approached to the surface of the SC under visual control and then was pushed by $5-10 \mu \mathrm{m}$. We observed that such a stimulus can indeed evoke sniffer GlyR activity and, hence, glycine release (Fig. $5 D)(n=3)$.

\section{Glycine is released from RC fibers}

To determine whether the glycine release evoked by a hypotonic solution can originate from RC fibers, we first compared, at E12.5, the percentage of glycine-ir RC fibers, located in the marginal zone of lumbar SC sections in control conditions ( 325 mosmol/ $\mathrm{kg} \mathrm{H}_{2} \mathrm{O}$ ACSF) or exposed to hypotonic ACSF $\left(200\right.$ mosmol $/ \mathrm{kg} \mathrm{H}_{2} \mathrm{O}$ ) with or without GlyT blockers (1 $\mu \mathrm{M}$ ALX-5407, a GlyT1 specific blocker, and $0.5 \mu \mathrm{M}$ ALX-1393, a blocker of both GlyT1 and GlyT2). A combined treatment with GlyT blockers and a hypotonic shock led to a complete loss of glycine immunoreactivity in RC fibers (Fig. 6A,B). Treatment with either GlyT blockers alone or hypotonic ACSF alone significantly reduced glycine immunoreactivity in RC fibers, but to a lesser extent than the combined treatment (Fig. 6C). Hypotonic solutions did not change taurine immunoreactivity detected in the marginal zone of the SC (data not shown), which confirms that taurine release is unlikely to be involved in the sniffer response.

Because RCs express GlyT1 only (Jursky and Nelson, 1996) and since GlyT blockers reduced the proportion of glycine-ir RC fibers, these results also indicate that glycine efflux could occur even in control conditions and that GlyT1 mediates glycine uptake rather than efflux even in the presence of a hypotonic solution. When penetrating the SC with the sniffer electrode, we observed an initial peak of activation followed by a slow decay (Fig. 4). It is likely that this initial peak reflects glycine release evoked when the electrode penetrates the SC (Fig. 5D). As shown in Figure 7, the decay rate of the sniffer current becomes faster at E14.5 than at E12.5 (Fig. 7A1-B1). The decay rate was estimated by measuring the duration of the sniffer current at $20 \%$ of the peak amplitude. The decay rate of the sniffer response was in the second time range at all age tested (Fig. 7) and did not change significantly between E11.5 and E13.5 (KruskalWallis rank sum test, $p>0.1$ ) (Fig. 7C). At E11.5, the 20\% peak amplitude duration was $62.4 \pm 9.8 \mathrm{~s}(n=7)$. The $20 \%$ peak amplitude duration was $84.4 \pm 12 \mathrm{~s}(n=21)$ at E12.5 and $54.8 \pm$ $11.6 \mathrm{~s}(n=12)$ at E13.5. It became significantly shorter at E14.5 $(20.6 \pm 3.4 s ; n=21)$ (Kruskal-Wallis rank sum test, $p<0.01$ ) (Fig. 7C). The decay rate of the sniffer response might then reflect some clearance mechanisms attributable to GlyT activity, which becomes more efficient at E14.5. This was confirmed by incubating SCs with the GlyT1 blocker ALX-5407, which resulted in a significant increase (Mann-Whitney test, $p<0.01$ ) in the decay rate of the sniffer current at E14.5 (Fig. 7D) and in the occurrence of a basal GlyR activation (Fig. 7B2), as observed in control conditions at E12.5 (Figs. 4A1, 7A1). These results suggest that GlyT1 transporter activity lowers the basal level of extracellular glycine concentration below the GlyR activation threshold at E14.5. It has also to be noted that ALX-5407 significantly increased (Man$\mathrm{n}-$ Whitney test, $p<0.01$ ) the decay rate of the sniffer current at E12.5 (Fig. 7C), indicating that some GlyT1 are already active at this age.

Together, our data, obtained using a multiple approach, clearly show that the spontaneous activation of GlyRs that was detected on motoneurons results from the release of glycine from RCs. 

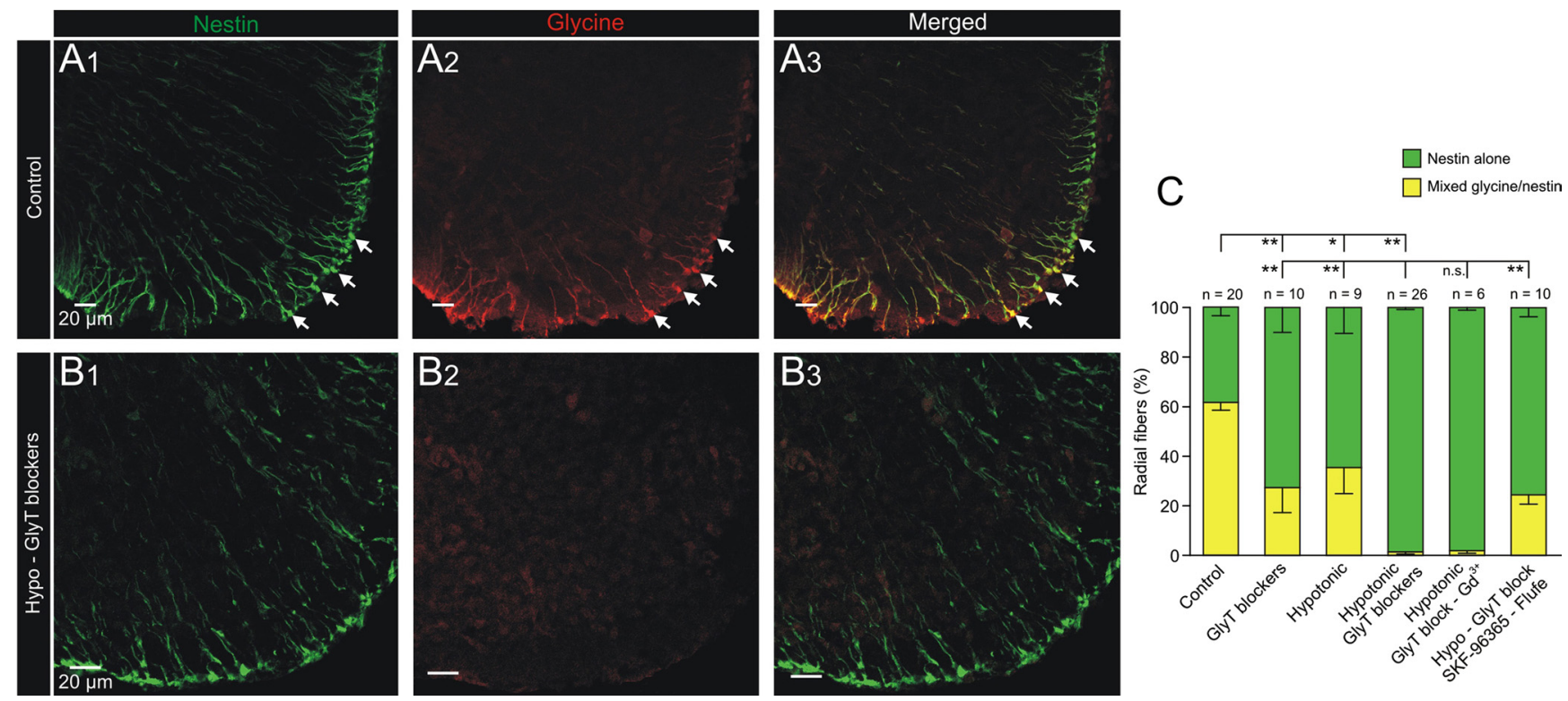

Figure 6. Glycine can be released by RCs in E12.5 embryonic spinal cords. A, Double immunostaining showing glycine-ir RCs in control conditions ( $325 \mathrm{mosmol} / \mathrm{kg} \mathrm{H} \mathrm{H}_{2} \mathrm{O}$. Anti-nestin (green) anti-glycine (red), and merged images are shown. Arrows, Examples of double-stained RC end feet. $\boldsymbol{B}$, Exposing the embryonic $\mathrm{SC}$ to $200 \mathrm{mosmol} / \mathrm{kg} \mathrm{H}_{2} 0$ solution during $1 \mathrm{~h}$ in the presence of $\mathrm{GlyT}$ blockers abolished the glycine labeling in nestin-ir RCs. Images are single $0.3-\mu \mathrm{m}$-thick confocal images. C, Variation in the proportion of double-stained glycine/nestin RC fibers according to various pharmacological treatments. Note that the simultaneous application of SKF-96365 and flufenamic acid partially reversed the effect induced by a hypotonic solution in the presence of GlyT blockers. Statistical tests are one-way ANOVA followed by a Dunnett's multiple comparison (test vs control or hypotonic/GlyT blockers: ${ }^{*} p<0.05 ;{ }^{* *} p<0.01$ ). The number of sections analyzed in each condition is indicated above the bars. Error bars indicate SEM.

\section{Glycine release from $\mathrm{RCs}$ and $\mathrm{Ca}^{2+}$}

The sniffer currents evoked by hypotonic solutions cannot result from glycine release attributable to action potential firing since they were still observed in the presence of TTX (Fig. $8 \mathrm{~A}$ ). Neurotransmitter release from RCs is related to $\mathrm{Ca}^{2+}$ influx, at least in the developing cortex (Weissman et al., 2004). We also found that glycine release evoked by hypotonic solutions partially requires $\mathrm{Ca}^{2+}$ influx (Fig. $8 \mathrm{~B}$ ). The reversible decrease in the sniffer response amplitude in the absence of external calcium (Fig. $8 B$ ) cannot result from a direct effect on GlyR activation. Indeed, the responses evoked by $100 \mu \mathrm{M}$ glycine application were not significantly (Wilcoxon's test, $p>0.1$ ) modified in the absence of external $\mathrm{Ca}^{2+}(95 \pm 5.9 \%$ of control; $n=4)$ (supplemental Fig. $5 A$, available at www.jneurosci.org as supplemental material). Since the application of a high $\left[\mathrm{K}^{+}\right]_{\mathrm{o}}$ solution failed to evoke a sniffer response, it is unlikely that voltage-gated $\mathrm{Ca}^{2+}$ channels are involved in glycine release from RCs. Hence we analyzed the effect of nonselective $\mathrm{Ca}^{2+}$ channel blockers $\mathrm{Gd}^{3+}(100 \mu \mathrm{M})$, SKF-96365 $(100 \mu \mathrm{M})$, and flufenamic acid (100 $\mu \mathrm{M}) \cdot \mathrm{Gd}^{3+}$ at 100 $\mu \mathrm{M}$ had no significant effect (Wilcoxon's test, $p>0.1$ ) on outside-out currents evoked by $100 \mu \mathrm{M}$ glycine application (93 \pm $7 \%$ of control; $n=4$ ) (supplemental Fig. $5 B$, available at www. jneurosci.org as supplemental material). $\mathrm{Gd}^{3+}$, SKF-96365, or flufenamic acid partially inhibited the sniffer response to a hypotonic shock. $\mathrm{Gd}^{3+}$ had a smaller effect than flufenamic acid (Fig. $8 C, D)$. The effects of SKF-96365 or flufenamic acid were irreversible (Fig. 8D,E) and were not attributable to a direct inhibition of GlyRs only (supplemental Fig. 5C,D, available at www.jneurosci. org as supplemental material). Effectively, although the coapplication of SKF-96365 and $100 \mu \mathrm{M}$ glycine or of flufenamic acid and $100 \mu \mathrm{M}$ glycine decreased outside-out current amplitudes by $86.3 \pm 8 \%(n=6)$ and $93.1 \pm 1 \%(n=3)$, respectively, these inhibitory effects of SKF-96365 and flufenamic acid were reversible (supplemental Fig. 5C,D, available at www.jneurosci.org as supplemental material). When glycine was applied $2 \mathrm{~min}$ after the coapplication of SKF-96365 and glycine or after the coapplication of flufenamic acid and glycine, the amplitude of the evoked outside-out currents was $96.5 \pm 6.5 \%(n=6)$ and $81 \pm 8 \%$ of control $(n=3)$, respectively.

We then used immunohistochemistry to test whether glycine release from RCs induced by a hypotonic challenge in the presence of GlyT blockers may be prevented by $\mathrm{Gd}^{3+}$, SKF-96365, and flufenamic acid. We quantified the proportion of RC fibers containing glycine in E12.5 lumbar SC exposed to the following: hypotonic shock, GlyT blockers, hypotonic shock/GlyT blockers with $\mathrm{Gd}^{3+}$ or SKF-96365/flufenamic acid (Fig. 6C). We found that, in the presence of $\mathrm{Gd}^{3+}(100 \mu \mathrm{M})$, there was a moderate but not significant increase in the percentage of RC fibers still containing glycine after hypotonic challenge with GlyT blockers $(1.9 \pm 1.0 \%, n=7$, vs $0.9 \pm 0.6 \%, n=25 ; p=0.08)$. The addition of SKF-96365 (100 $\mu \mathrm{M})$ and flufenamic acid (100 $\mu \mathrm{M})$ had a stronger effect than $\mathrm{Gd}^{3+}$. These blockers increased $>10$ times $(p<0.01)$ the proportion of glycine-ir RC fibers after hypotonic challenge in the presence of GlyT blockers $(24.4 \pm$ $3.7 \% ; n=10$ ) (Fig. 6C).

\section{Nonvesicular release of glycine from RCs}

Because glycine release, evoked in response to hypotonic shock, was reduced in the absence of external $\mathrm{Ca}^{2+}$, we supposed that it could reflect vesicular release of glycine. To test whether glycine release is vesicular, we analyzed the effect of preincubation (during $1-3 \mathrm{~h}$ at $35^{\circ} \mathrm{C}$ ) with $4 \mu \mathrm{M}$ bafilomycin $\mathrm{A} 1$, an inhibitor of the $\mathrm{V}$ (vacuolar)-ATPase that prevents the entrance of neurotransmitters into synaptic vesicles (Cousin and Nicholls, 1997). Glycine release evoked by hypotonic shock was analyzed using sniffer patches in E14.5 SCs because many synapses are functional at this embryonic age. We first analyzed the effect of this toxin on the spontaneous and evoked synaptic activity (elevated $\left[\mathrm{K}^{+}\right]_{\mathrm{o}}$ ) recorded on spinal MNs (Fig. 9A1, A2). The application of $30 \mathrm{~mm}$ $\mathrm{KCl}$ dramatically increased the frequency of postsynaptic events 
(Fig. 9A1) and preincubation with bafilomycin was able to completely eliminate spontaneous and evoked PSCs $(n=6)$, indicating that synaptic vesicular release was impaired (Fig. 9A2). In these preparations, the hypotonic solution was still able to evoke a sniffer current (Fig. 9A3), suggesting that glycine released by this method is unlikely to be vesicular.

In addition, we could not detect immunoreactivity for the vesicular inhibitory amino acid transporters (VIAATs) for glycine inside glycine-ir RCs (supplemental Fig. 6, available at www.jneurosci. org as supplemental material), reinforcing the hypothesis of a nonvesicular release of glycine from RCs.

Glycine release could alternatively result from the opening of large channels in response to membrane stretch such as hemichannels formed by connexins or pannexins, $\mathrm{P}_{2} \mathrm{X}_{7}$ receptors, and/or the TRPV1 (Suadicani et al., 2006; Chung et al., 2008; Iovine et al., 2008). Unopposed hemichannels are present on RCs in the cortex of fetal rats (Elias et al., 2007). Other proteins such as the noncanonical connexin C23 (Iovine et al., 2008) or the TRPV1 (Chung et al., 2008) can also allow the permeation of small molecules. In that context, it is important to notice that flufenamic acid can block connexins (Weissman et al., 2004), $\mathrm{P} 2 \mathrm{X}_{7}$ receptors (Suadicani et al., 2006), and transient receptor potential (TRP) channels (for review, see Pedersen and Nilius, 2007).

We therefore determined whether functional hemichannels and $\mathrm{P} 2 \mathrm{X}_{7}$ receptors are present on SC RCs by using a classical procedure to reveal the presence of connexin or pannexin hemichannels on RCs in the SC of fetal mice at E12.5-E13.5. Radial cell bodies are located in the median zone of the ventromedian part of the lumbar SC. Hemichannels are permeable to the small anionic fluorescent dye LY [molecular weight (MW) 457] or to the cationic Neurobiotin (MW 322). LY can pass through connexons or pannexons (Shestopalov and Panchin, 2008) as well as through $\mathrm{P}_{2} \mathrm{X}_{7}$ receptors (Colomar and Amédée, 2001), and Neurobiotin can pass through hemichannels formed by connexin C23 (Iovine et al., 2008). In control conditions ( $325 \mathrm{mosmol} / \mathrm{kg} \mathrm{H}_{2} \mathrm{O}$ ), some cells ( $22.5 \pm 2.5$ cells; $n=12$ slices; 4 lumbar slices per SC; 3 SCs) displayed a low LY staining. Applying a hypotonic solution $\left(200 \mathrm{mosmol} / \mathrm{kg} \mathrm{H}_{2} \mathrm{O}\right)$ did not significantly change (Mann-Whitney test, $p>0.05$ ) LY uptake by cells located in the ventromedian part of the lumbar SC $(15.3 \pm 3.1$ cells; $n=12$ slices; 4 lumbar slices per SC; 3 SCs) (supplemental Fig. 7A, available at www.jneurosci.org as supplemental material). In control conditions ( $325 \mathrm{mosmol} / \mathrm{kg} \mathrm{H}_{2} \mathrm{O}$ ), very few cells displayed Neurobiotin staining in the ventromedian part of the lumbar SC ( $1.7 \pm 0.4$ cells; $n=12$ slices; 4 lumbar slices per SC; 3 SCs). Applying a hypotonic solution (200 mosmol/ $\mathrm{kg} \mathrm{H}_{2} \mathrm{O}$ )
A2

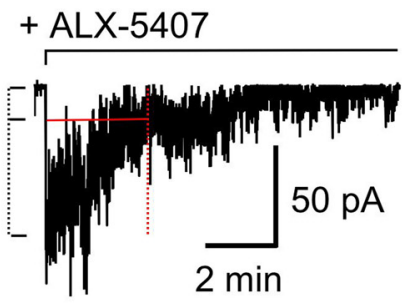

B2
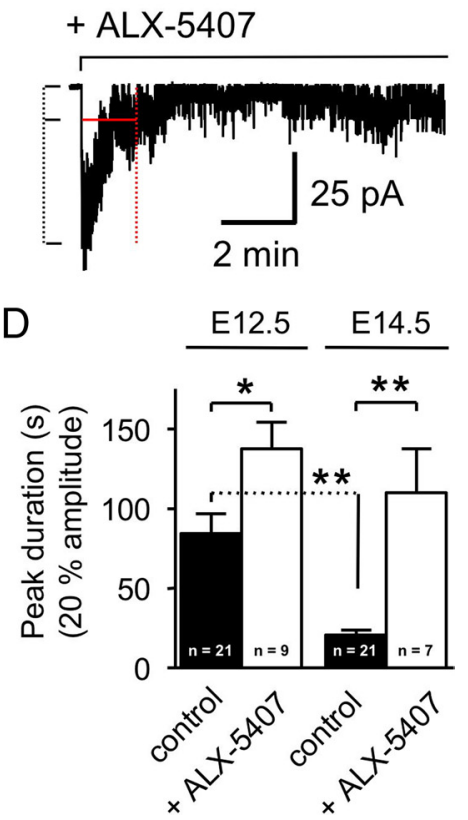

Figure 7. Glycine transporter GlyT1 participates in glycine clearance from the extracellular space. $\boldsymbol{A 1}, \mathbf{B 1}$, Examples of sniffer responses recorded atE12.5 (A1) and at E14.5 (B1) in the absence of the GlyT1 blocker ALX-5407. The sniffer response time course was estimated by measuring the duration of the sniffer current at $20 \%$ of the peak amplitude of the deactivation phase of the sniffer current. Note that the deactivation time course of the outside-out currents recorded atE14.5 became considerably faster than atE12.5 and that channel activity of locker, on the time course of the sniffer current atE12.5 (A2) and atE14.5 (B2). Note that the application of ALX-5407 atE14.5 considerably hened the sniffer response (B2).C, The 20\% peak amplitude duration of the sniffer current from E11.5 to E14.5. Note that the 20\% 作 different between E12.5 and E14.5 (Mann-Whitney test, $p>0.1$ ). Error bars indicate SEM.

did not significantly change (Mann-Whitney test, $p>0.05)$ the number of cells displaying Neurobiotin staining $(0.8 \pm 0.2$ cells; $n=12$ slices; 4 lumbar slices per SC; 3 SCs) (supplemental Fig. $7 B$, available at www.jneurosci.org as supplemental material). Moreover, $20 \mu \mathrm{M}$ ATP application (P2X receptor agonist) did not evoke any GlyR sniffer activation $(n=4)$, and neither did $10 \mu \mathrm{M}$ capsaicin, a TRPV1 agonist $(n=4)$ (supplemental Fig. $7 C$, available at www.jneurosci.org as supplemental material). Accordingly, these findings do not support the implication of hemiconnexins, $\mathrm{P} 2 \mathrm{X}$ or TRPV1 receptors in glycine release.

We have shown that flufenamic acid and SKF-96365 partially inhibit the sniffer response to a hypotonic shock (Fig. 8D,E). Flufenamic acid is also known to block chloride channels (Do et al., 2006; Greenwood and Leblanc, 2007). Hence, it seems possible that volume-sensitive chloride channels may also be involved in 
A
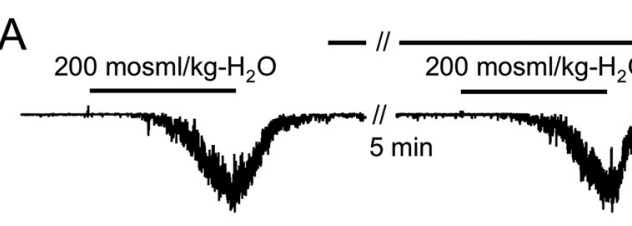

$1 \mu \mathrm{M}$ TTX

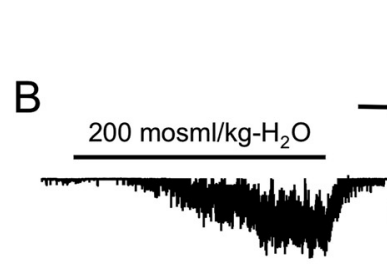

$$
-\| \frac{0\left[\mathrm{Ca}^{2+}\right]_{0} \text { saline }}{\frac{200 \mathrm{mosml} / \mathrm{kg}-\mathrm{H}_{2} \mathrm{O}}{5 \mathrm{~min}}}
$$

$200 \mathrm{mosml} / \mathrm{kg}-\mathrm{H}_{2} \mathrm{O}$

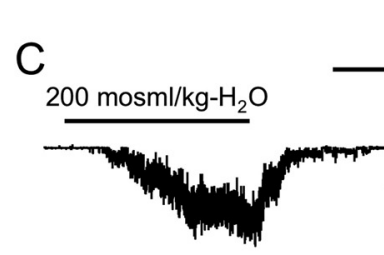

$-/ / \frac{100 \mu \mathrm{M} \mathrm{Gd}^{3+}}{200 \mathrm{mosml} /{\mathrm{kg}-\mathrm{H}_{2} \mathrm{O}}^{3}}$

$50 \mathrm{pA}$

$2 \min$

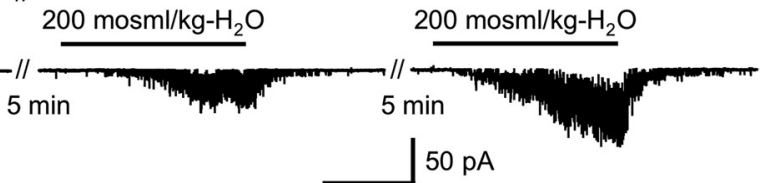

2 min

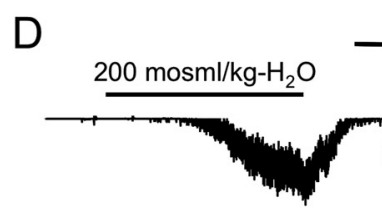

$-\| \frac{100 \mu \mathrm{M} \text { Flufenamic acid }}{200 \mathrm{mosml} / \mathrm{kg}-\mathrm{H}_{2} \mathrm{O}}$

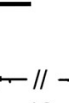

$200 \mathrm{mosml} / \mathrm{kg}-\mathrm{H}_{2} \mathrm{O}$

$5 \min$

$10 \mathrm{~min}$

$100 \mathrm{pA}$

$2 \min$

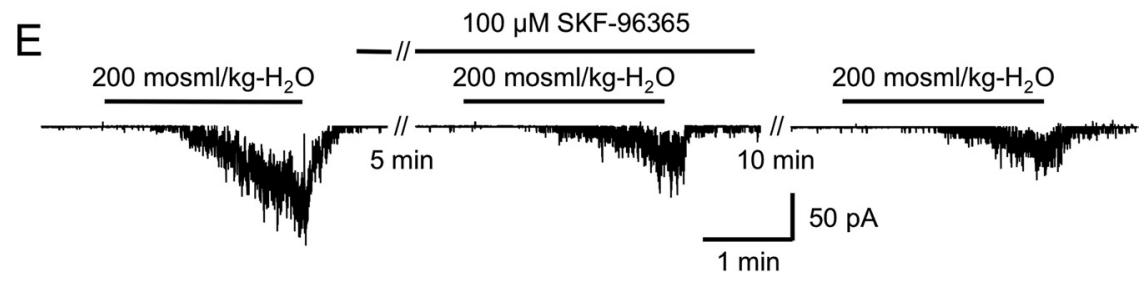

Figure 8. Effect of TTX, low $\left[\mathrm{Ca}^{2+}\right]_{0}, \mathrm{Gd}^{3+}$, flufenamic acid, or SKF-96365 on glycine release evoked by the application of a hypotonic solution. $A$, TTX application did not significantly change the amplitude of the sniffer currents ( $105.8 \pm 9.8 \%$ of control; $n=5$ ) evoked by the application of a hypotonic solution, indicating that the glycine release evoked by membrane stretch caused by cell swelling is independent of $\mathrm{Na}^{+}$action potential firing. $\boldsymbol{B}$, To determine whether glycine release evoked by hypotonic solution is dependent on external $\mathrm{Ca}^{2+}$, we analyzed the effect of a low $\mathrm{Ca}^{2+}$ external solution $\left(0 \mathrm{~mm}\left[\mathrm{Ca}^{2+}\right]_{0}\right.$ and $1 \mathrm{~mm}$ EGTA). The amplitude of the evoked sniffer current was significantly (Wilcoxon's test, $p<0.01$ ) and reversibly decreased by $56.9 \pm 11 \%$ $(n=4)$ in the presence of $\mathrm{Ca}^{2+}$-free solution, indicating that glycine release in response to membrane stretch necessitates $\mathrm{Ca}^{2+}$ influx. C, Application of $100 \mu \mathrm{m}$ gadolinium $\left(\mathrm{Gd}^{3+}\right)$ reversibly inhibited the sniffer response to hypotonic shock by $61.2 \pm 7.4 \%$ $(n=4) . \boldsymbol{D}, E, A$ single application (2-4 min) of $100 \mu \mathrm{m}$ flufenamic acid or $100 \mu \mathrm{m}$ SKF-96365 evoked an inhibition of the sniffer response by $89.1 \pm 2.6 \%(n=5)$ and $81.6 \pm 5.4 \%(n=8)$, respectively. The sniffer responses induced by hypotonic solution were still decreased $10 \mathrm{~min}$ after the end of the application of these inhibitors. This was not attributable to direct inhibition of glycine-evoked responses (supplemental Fig. 7, available at www.jneurosci.org as supplemental material). Ten minutes after the end of the application of flufenamic acid and SKF-96365, sniffer response were decreased by $81.4 \pm 7.3$ and $62.4 \pm 4.6 \%$, respectively. The inhibition evoked by flufenamic acid still remains significantly higher than $\mathrm{Gd}^{3+}$-evoked inhibition (MannWhitney test, $p<0.05)$. In two sniffer patches, we found that inhibition of the sniffer responses still occurred 20 min after washing out SKF-96365 or flufenamic acid (data not shown).

glycine release. For example, VSOR anion channels have been suggested to release small molecules after mechanical stimuli (Liu et al., 2008). We looked for a possible involvement of VSOR in glycine release from RCs, by quantifying the proportion of RC fibers containing glycine in E12.5 lumbar SC in control condition or having been exposed to hypotonic shock/GlyT blockers in the absence or in the presence of DCPIB, a specific blocker of VSOR channels (Liu et al., 2008).
In the presence of DCPIB $(10 \mu \mathrm{M})$, there was a significant increase in the percentage of RC fibers containing glycine after hypotonic challenge with GlyT blockers when compared with data obtained after hypotonic challenge with GlyT blockers in the absence of DCPIB $(49.3 \pm 3.8 \%$, $n=14$, vs $1.1 \pm 0.6 \%, n=28 ; p<0.01$, Dunnett's multiple comparison after oneway ANOVA) (Fig. 9B). Interestingly, this percentage in DCPIB-treated preparations was not significantly different from control $(57.8 \pm 3.4 \% ; n=23)$. Similar results were obtained with $10 \mu \mathrm{M}$ phloretin, another blocker of VSOR channels (Liu et al., 2008): phloretin significantly increased the percentage of glycine-ir RC fibers detected after a hypotonic shock with GlyT blockers $(32.5 \pm 4.3 \%, n=4$, vs $1.1 \pm 0.6 \%, n=28$; $p<0.01$, Dunnett's multiple comparison) (Fig. 9B4). The percentage of RC fibers in phloretin-treated preparations was also not significantly different from control. Hence, we analyzed the effect of DCPIB $(10 \mu \mathrm{M})$ and phloretin $(10 \mu \mathrm{M})$ on the sniffer response to a hypotonic shock (supplemental Fig. $7 D, E$, available at www.jneurosci.org as supplemental material). Both DCPIB and phloretin inhibited the sniffer response to a hypotonic shock $(86.7 \pm 5.9 \%$ block for DCPIB, $n=5$, and $78.3 \pm 11.8 \%$ block for phloretin, $n=3$ ). This was not attributable to direct inhibition of glycine-evoked responses (supplemental Fig. 5, available at www.jneurosci.org as supplemental material) at least for DCPIB. Indeed, the sniffer responses induced by hypotonic solution were still decreased $10 \mathrm{~min}$ after the end of the application of DCPIB $(80.5 \pm 8 \%$ block; $n=5$ ). This was significantly different (Mann-Whitney test, $p<0.01$ ) from the decrease in GlyR activation observed $10 \mathrm{~min}$ after the end of DCPIB application (23.1 \pm $5.6 \% ; n=9)$. The inhibition of the sniffer response evoked by phloretin was also poorly reversible. We observed a $76.7 \pm$ $11.1 \%$ inhibition $(n=3) 10 \mathrm{~min}$ after the end of the application of this drug (supplemental Fig. $7 E$, available at www.jneurosci. org as supplemental material). However, phloretin-evoked inhibition of GlyR activation was also poorly reversible (64.1 \pm $7.1 \% ; n=6$ ) (supplemental Fig. 5F, available at www.jneurosci.org as supplemental material), which precluded making any conclusion on the effect of phloretin on glycine release using the sniffer recording technique.

Functional relevance of early glycine release from RCs Glycine has been described as the transmitter system required, with $\mathrm{ACh}$, for the propagation of the spontaneous rhythmic activity in E12.5 embryonic mouse spinal cord (Hanson and Landmesser, 2003). We performed multiple extracellular recordings 

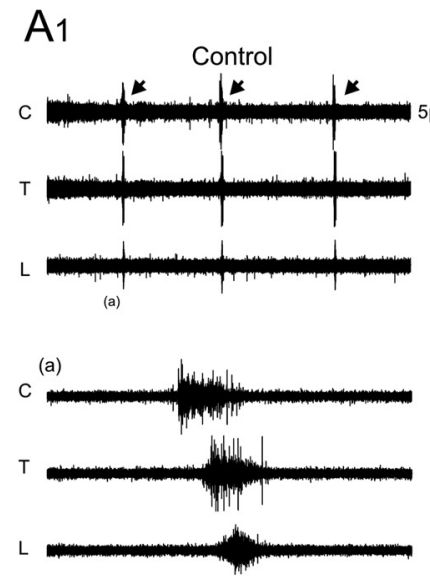
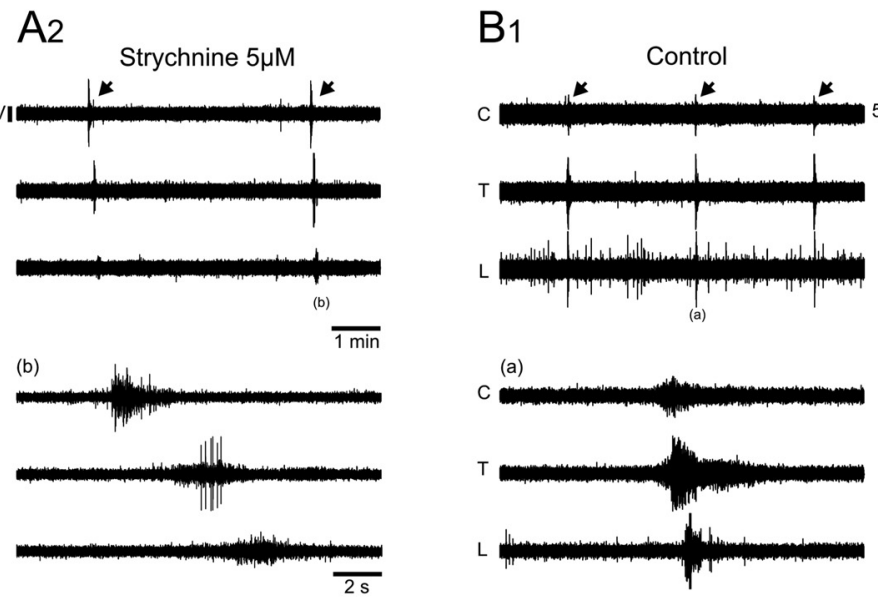

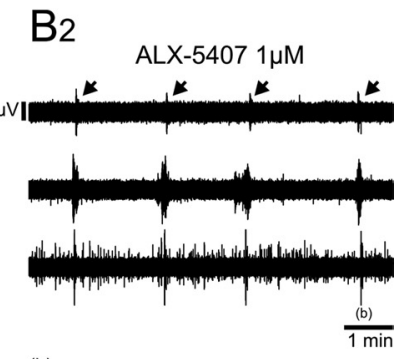

(b)

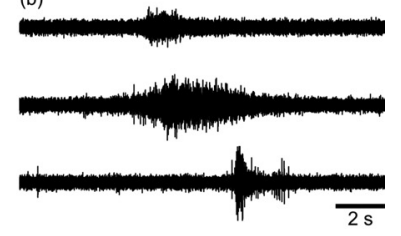

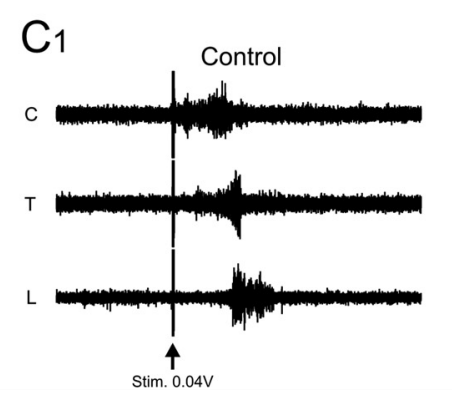
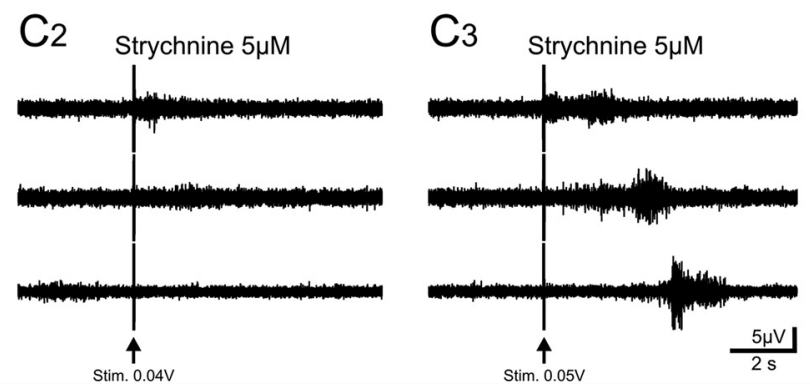

Figure 10. Glycine release controls the spontaneous activity at E12.5. A, Simultaneous extracellular recordings of spontaneous activity at cervical (C), thoracic (T), and lumbar (L) levels from E12.5 spinal cords in the absence $(\boldsymbol{A 1})$ and in the presence $(\boldsymbol{A 2})$ of strychnine. Strychnine (5 $\mu \mathrm{m})$ slowed down the frequency of spontaneous activity simultaneously recorded at cervical ( $\mathrm{C})$, thoracic (T), and lumbar (L) levels from E12.5 spinal cords. Note the reduction of the burst intensity and the decrease of the rostrocaudal propagation speed in the presence of strychnine. The arrows point at recurring bursts of activity. B, Blocking GlyT1 by ALX-5407 (1 $\mu \mathrm{m})$ accelerated the spontaneous activity frequency and increased the burst intensity. $\boldsymbol{C}$, Rostrocaudal propagation of bursts of activity evoked by electrical stimulation $(0.04 \mathrm{~V}$ ) at the cervical level (closed to the cervical recording electrode) could be blocked by strychnine when using threshold intensity ( $\mathbf{C}$ ) but was restored when slightly increasing the intensity of stimulation $(0.05 \mathrm{~V})(\mathbf{C} 3)$. Note the longer propagation delay in the presence of strychnine.

stages of the SC development. Radial cells are involved in cell migration and are potent neuronal and glial progenitors (Pinto and Götz, 2007). Here, we also give evidences that this release of glycine at E12.5 modulates the propagation of the spontaneous activity in the isolated embryonic spinal cord.

Taurine was initially proposed as the main GlyR agonist in the developing CNS (Flint et al., 1998), but we found no evidence for taurine release in the embryonic SC. Indeed, taurine immunoreactivity was restricted to the marginal zone and was not expressed by RCs. Also, taurine immunoreactivity did not disappear in the presence of a hypotonic solution, which makes it unlikely that taurine is released by osmotic changes. Therefore, we propose that glycine is the main endogenous GlyR agonist at early developmental stages of the SC neuronal networks, and this is reinforced by the fact that the extracellular endogenous GlyR agonist concentration is enhanced in the presence of GlyT blockers.

\section{Radial cells are the main source of glycine before E13.5}

Both neuroepithelial cells and glial cell progenitors share similar, radial, morphology. They also share expression of the intermediate filament nestin and the antigen for RC2 (Pinto and Götz, 2007). In the mouse spinal cord, neuroepithelial cells appear at the onset of the neurogenesis (E10), whereas radial glial cells occur at E12/E13 when neurogenesis comes to an end (Barry and McDermott, 2005). Since the proportion of glycine-ir radial cells increases from E11.5 to E13.5 and since almost all radial cells contain glycine at E13.5 (>80\%), we assume that they are radial glial cells. At E12.5, RCs appear to be the exclusive source of glycine, glycinergic neurons being detected at E13.5 at more caudal spinal levels only (Allain et al., 2006). After E13.5, the proportion of RCs expressing glycine declines. This temporary expression of glycine in RCs may rely on several mechanisms that are not mutually exclusive. The first possibility is a developmental change in the efficacy of radial cells in glycine (re) uptake. The expression of GlyT1 by spinal radial cells in fetal mice increases from E11.5 to E13.5 and then declines at later stages (Jursky and Nelson, 1996), which could suggest that radial cell glycine content originates from glycine uptake. The second possibility is a developmentally regulated synthesis of glycine by differentiating radial cells. Glycine is mainly formed via a complex metabolic pathway in astroglia (Furuya et al., 2000) to provide a microenvironment for optimal neuronal network development and operation (de Koning et al., 2003).

Release of glycine and mechanical stimuli

Nonvesicular release was described for GABA and glutamate in the developing cortex (Liu et al., 2005) and hippocampus (Demarque et al., 2002; Le Meur et al., 2007). We show here that the glycine release by RCs after a hypotonic shock is also nonvesicular. Because of its transport stoichiometry $\left(2 \mathrm{Na}^{+} / 1 \mathrm{Cl}^{-} / 1\right.$ glycine) (Aragón et al., 1987), GlyT1 can take up or release glycine depending on the concentration of $\mathrm{Na}^{+}$or glycine and on the membrane potential (Roux and Supplisson, 2000; Huang et al., 2004). Although we cannot completely rule out the possibly that GlyT1 also participates in glycine release from RCs in the embryonic SC, it is unlikely to be the major mechanism. Indeed, blocking GlyT1 decreases the proportion of glycine-ir RCs, indicating 
that the main function of the glycine transporters is more likely to be (re)uptake of glycine into RC fibers.

Glycine release could be induced by mechanical stimuli and by hypotonic shocks. Neurotransmitter release in response to mechanical stimuli in the embryo is still poorly understood, and the corresponding physiological stimulus is unclear. However, there is evidence suggesting that, at least in the developing cortex, blood circulation through blood vessels could result in RC fiber deformation (RCs extend intermediate branches around blood vessels) and, hence, evoke neurotransmitter release (Weissman et al., 2004). Cellular membrane deformation was also proposed to explain mechanical-dependent release of GABA by astrocytes in the olfactory bulbs of young rats (Kozlov et al., 2006). Accordingly, because RCs include astroglial progenitors (Pinto and Götz, 2007), one may suppose that astrocytes maintain during development a release mechanism already present in their precursor cells.

Another possible mechanical stimulus, although slow, could be RC fiber local deformation during the migration of the newborn neurons. Newly formed interneurons migrate from E10.5 to E13.5 in the ventral horn (Goulding and Pfaff, 2005) and neuronal migration could evoke mechanical stimuli and deformation of radial cell fibers (Kriegstein and Noctor, 2004). Finally, a last potential physiological stimulus could be the flow of the CSF (Vígh et al., 2004) since radial cell fiber endings are located close to the pial surface of the SC. Additional experiments will be necessary to address this issue.

\section{Glycine release mechanism(s)}

Neurotransmitter release by mechanical stimuli was previously described in the adult and in the developing CNS in slices (Flint et al., 1998; Kozlov et al., 2006), but the release pathway remained to be determined. One of the major problems to characterize the release pathway involved in nonvesicular release of neurotransmitter is the lack of strong specificity of the channel blockers generally used to analyze the implication of TRPs, hemichannels, P2XRs, and volume-sensitive chloride channels. For example, flufenamic acid has been described as a TRP channel blocker (Inoue et al., 2001; Lee et al., 2003), although it also interferes with connexin/pannexin hemichannels, with P2X receptors (Lee et al., 2001; Weissman et al., 2004) and with GlyRs (supplemental Fig. 5, available at www.jneurosci.org as supplemental material). To overcome this problem, we used a multiple approach, which allowed us to exclude $\mathrm{P} 2 \mathrm{X}$ receptors, TRPV1 receptors, and hemichannels as potential release pathways for glycine. Moreover, $\mathrm{Gd}^{3+}$, also known to be a potent TRP blocker (Hamill and McBride, 1996; Cho et al., 2002), did not prevent loss of glycine content from RCs, which makes unlikely that TRP activation is involved in glycine release by RCs.

Accordingly, the last known candidate allowing glycine release could be the VSOR anion channels (Liu et al., 2008) or the maxi anion channels (Liu et al., 2006). Release of small molecules such as ATP or glutamate, evoked by mechanical stimuli, can also involve VSOR anion channels or maxi anion channels at least in vitro (Liu et al., 2006, 2008). Since we were able to prevent the decrease in RC glycine content evoked by hypotonic solution using DCPIB and phloretin, two blockers of VSOR channels, and since VSOR channels are poorly blocked by $\mathrm{Gd}^{3+}$ (Decher et al., 2001), we propose that glycine release involves mainly the opening of VSOR channels. VSOR channels have a small pore radius $(\approx 0.63 \mathrm{~nm}$ ) allowing efflux of small amino acids only (Ternovsky et al., 2004), such as glycine. Accordingly, the opening of VSOR channels cannot be detected during uptake experiments using bigger molecules such as LY or Neurobiotin.

We also showed that glycine release is partly dependent on $\mathrm{Ca}^{2+}$ influx, but, since glycine release cannot be evoked by high $\left[\mathrm{K}^{+}\right]_{\mathrm{o}}$ solutions, it is unlikely to involve voltage-gated $\mathrm{Ca}^{2+}$ channels. We therefore cannot entirely exclude that glycine release is also modulated by voltage-independent $\mathrm{Ca}^{2+}$ channels (Christensen and Corey, 2007), but it is interesting to mention that VSOR channel openings are also evoked by increasing $\left[\mathrm{Ca}^{2+}\right]_{\mathrm{i}}$ and by activation of PLC1 (Varela et al., 2007).

\section{Glycine release and functional early developing neuronal network}

Glycine synaptic release in the early mouse embryonic SC (E12.5) has been proposed to be involved in the genesis of recurrent episodes of spontaneous activity and their propagation along the SC (Branchereau et al., 2002; Hanson and Landmesser, 2003). This proposal was based on extracellular recordings and on pharmacological studies using GlyR antagonists in vitro. However, we show that glycinergic synaptic activity does not occur at E12.5 ruling out the possibility that a glycine synaptic network can be involved in the intersegmental propagation of the spontaneous electrical activity in the embryonic SC at this early stage. The first functional synapses occur at E13.5 in the embryonic mouse lumbar SC and are GABAergic, being consistent with what is known in other areas of the CNS (Ben-Ari, 2001). The lack of glycinergic synaptic events is also consistent with the very low proportion of glycinergic neurons detected at E12.5 (Allain et al., 2006). We demonstrated that blocking GlyRs by strychnine depressed the spontaneous activity, whereas increasing the glycine concentration by ALX-5407 boosted it. We therefore propose that fluctuations of basal glycine concentrations, likely to be released from RCs, influence the excitability of developing neural networks, thereby modulating the propagation speed and the likelihood of spontaneous activity propagating along the SC (Hanson and Landmesser, 2003; Ren and Greer, 2003; Yvert et al., 2004).

\section{References}

Allain AE, Baïri A, Meyrand P, Branchereau P (2006) Expression of the glycinergic system during the course of embryonic development in the mouse spinal cord and its co-localization with GABA immunoreactivity. J Comp Neurol 496:832-846.

Aragón MC, Giménez C, Mayor F (1987) Stoichiometry of sodium- and chloride-coupled glycine transport in synaptic plasma membrane vesicles derived from rat brain. FEBS Lett 212:87-90.

Barry D, McDermott K (2005) Differentiation of radial glia from radial precursor cells and transformation into astrocytes in the developing rat spinal cord. Glia 50:187-197.

Ben-Ari Y (2001) Developing networks play a similar melody. Trends Neurosci 24:353-360.

Ben-Ari Y, Khalilov I, Represa A, Gozlan H (2004) Interneurons set the tune of developing networks. Trends Neurosci 27:422-427.

Bordey A (2007) Enigmatic GABAergic networks in adult neurogenic zones. Brain Res Rev 53:124-134.

Branchereau P, Chapron J, Meyrand P (2002) Descending 5-hydroxytryptamine raphe inputs repress the expression of serotonergic neurons and slow the maturation of inhibitory systems in mouse embryonic spinal cord. J Neurosci 22:2598-2606

Chavas J, Forero ME, Collin T, Llano I, Marty A (2004) Osmotic tension as a possible link between $\mathrm{GABA}_{\mathrm{A}}$ receptor activation and intracellular calcium elevation. Neuron 44:701-713.

Cho H, Shin J, Shin CY, Lee SY, Oh U (2002) Mechanosensitive ion channels in cultured sensory neurons of neonatal rats. J Neurosci 22:1238-1247.

Christensen AP, Corey DP (2007) TRP channels in mechanosensation: direct or indirect activation? Nat Rev Neurosci 8:510-521. 
Chung MK, Güler AD, Caterina MJ (2008) TRPV1 shows dynamic ionic selectivity during agonist stimulation. Nat Neurosci 11:555-564.

Colomar A, Amédée T (2001) ATP stimulation of P2X $\mathrm{X}_{7}$ receptors activates three different ionic conductances on cultured mouse Schwann cells. Eur J Neurosci 14:927-936.

Cousin MA, Nicholls DG (1997) Synaptic vesicle recycling in cultured cerebellar granule cells: role of vesicular acidification and refilling. J Neurochem 69:1927-1935.

Decher N, Lang HJ, Nilius B, Brüggemann A, Busch AE, Steinmeyer K (2001) DCPIB is a novel selective blocker of $\mathrm{I}(\mathrm{Cl}$, swell $)$ and prevents swellinginduced shortening of guinea-pig atrial action potential duration. $\mathrm{Br} \mathrm{J}$ Pharmacol 134:1467-1479.

de Koning TJ, Snell K, Duran M, Berger R, Poll-The BT, Surtees R (2003) L-Serine in disease and development. Biochem J 371:653-661.

Delpy A, Allain AE, Meyrand P, Branchereau P (2008) NKCC1 inactivation underlies embryonic development of chloride-mediated inhibition in mouse spinal motoneuron. J Physiol 586:1059-1075.

Demarque M, Represa A, Becq H, Khalilov I, Ben-Ari Y, Aniksztejn L (2002) Paracrine intercellular communication by $\mathrm{a} \mathrm{Ca}^{2+}$ and SNAREindependent release of GABA and glutamate prior to synapse formation. Neuron 36:1051-1061.

De Saint Jan D, David-Watine B, Korn H, Bregestovski P (2001) Activation of human alpha1 and alpha2 homomeric glycine receptors by taurine and GABA. J Physiol 535:741-755.

Do CW, Peterson-Yantorno K, Civan MM (2006) Swelling-activated $\mathrm{Cl}^{-}$ channels support $\mathrm{Cl}^{-}$secretion by bovine ciliary epithelium. Invest Ophthalmol Vis Sci 47:2576-2582.

Elias LA, Wang DD, Kriegstein AR (2007) Gap junction adhesion is necessary for radial migration in the neocortex. Nature 448:901-907.

Ericson J, Thor S, Edlund T, Jessell TM, Yamada T (1992) Early stages of motor neuron differentiation revealed by expression of homeobox gene Islet-1. Science 256:1555-1560.

Flint AC, Liu X, Kriegstein AR (1998) Nonsynaptic glycine receptor activation during early neocortical development. Neuron 20:43-53.

Furuya S, Tabata T, Mitoma J, Yamada K, Yamasaki M, Makino A, Yamamoto T, Watanabe M, Kano M, Hirabayashi Y (2000) L-Serine and glycine serve as major astroglia-derived trophic factors for cerebellar Purkinje neurons. Proc Natl Acad Sci U S A 97:11528-11533.

Goulding M, Pfaff SL (2005) Development of circuits that generate simple rhythmic behaviors in vertebrates. Curr Opin Neurobiol 15:14-20.

Greenwood IA, Leblanc N (2007) Overlapping pharmacology of $\mathrm{Ca}^{2+}$ activated $\mathrm{Cl}^{-}$and $\mathrm{K}^{+}$channels. Trends Pharmacol Sci 28:1-5.

Gu X, Spitzer NC (1997) Breaking the code: regulation of neuronal differentiation by spontaneous calcium transients. Dev Neurosci 19:33-41.

Hamill OP, McBride DW Jr (1996) The pharmacology of mechanogated membrane ion channels. Pharmacol Rev 48:231-252.

Hanson MG, Landmesser LT (2003) Characterization of the circuits that generate spontaneous episodes of activity in the early embryonic mouse spinal cord. J Neurosci 23:587-600.

Hartfuss E, Galli R, Heins N, Götz M (2001) Characterization of CNS precursor subtypes and radial glia. Dev Biol 229:15-30.

Huang H, Barakat L, Wang D, Bordey A (2004) Bergmann glial GlyT1 mediates glycine uptake and release in mouse cerebellar slices. J Physiol 560:721-736.

Inoue R, Okada T, Onoue H, Hara Y, Shimizu S, Naitoh S, Ito Y, Mori Y (2001) The transient receptor potential protein homologue TRP6 is the essential component of vascular alpha(1)-adrenoceptor-activated $\mathrm{Ca}^{2+}$. permeable cation channel. Circ Res 88:325-332.

Iovine MK, Gumpert AM, Falk MM, Mendelson TC (2008) Cx23, a connexin with only four extracellular-loop cysteines, forms functional gap junction channels and hemichannels. FEBS Lett 582:165-170.

Jursky F, Nelson N (1996) Developmental expression of the glycine transporters GLYT1 and GLYT2 in mouse brain. J Neurochem 67:336-344.

Kozlov AS, Angulo MC, Audinat E, Charpak S (2006) Target cell-specific modulation of neuronal activity by astrocytes. Proc Natl Acad Sci U S A 103:10058-10063.

Kriegstein AR, Noctor SC (2004) Patterns of neuronal migration in the embryonic cortex. Trends Neurosci 27:392-399.

Lee JH, Chiba T, Marcus DC (2001) P2X 2 receptor mediates stimulation of parasensory cation absorption by cochlear outer sulcus cells and vestibular transitional cells. J Neurosci 21:9168-9174.
Lee YM, Kim BJ, Kim HJ, Yang DK, Zhu MH, Lee KP, So I, Kim KW (2003) TRPC5 as a candidate for the nonselective cation channel activated by muscarinic stimulation in murine stomach. Am J Physiol Gastrointest Liver Physiol 284:G604-G616.

Le Meur K, Galante M, Angulo MC, Audinat E (2007) Tonic activation of NMDA receptors by ambient glutamate of non-synaptic origin in the rat hippocampus. J Physiol 580:373-383.

Liu HT, Tashmukhamedov BA, Inoue H, Okada Y, Sabirov RZ (2006) Roles of two types of anion channels in glutamate release from mouse astrocytes under ischemic or osmotic stress. Glia 54:343-357.

Liu HT, Toychiev AH, Takahashi N, Sabirov RZ, Okada Y (2008) Maxianion channel as a candidate pathway for osmosensitive ATP release from mouse astrocytes in primary culture. Cell Res 18:558-565.

Liu X, Wang Q, Haydar TF, Bordey A (2005) Nonsynaptic GABA signaling in postnatal subventricular zone controls proliferation of GFAPexpressing progenitors. Nat Neurosci 8:1179-1187.

Mangin JM, Baloul M, Prado De Carvalho L, Rogister B, Rigo JM, Legendre P (2003) Kinetic properties of the alpha2 homo-oligomeric glycine receptor impairs a proper synaptic functioning. J Physiol 553:369-386.

Muller E, Le Corronc H, Triller A, Legendre P (2006) Developmental dissociation of presynaptic inhibitory neurotransmitter and postsynaptic receptor clustering in the hypoglossal nucleus. Mol Cell Neurosci 32:254-273.

O'Donovan MJ (1999) The origin of spontaneous activity in developing networks of the vertebrate nervous system. Curr Opin Neurobiol 9:94-104.

O’Donovan MJ, Chub N, Wenner P (1998) Mechanisms of spontaneous activity in developing spinal networks. J Neurobiol 37:131-145.

Pedersen SF, Nilius B (2007) Transient receptor potential channels in mechanosensing and cell volume regulation. Methods Enzymol 428:183-207.

Pinto L, Götz M (2007) Radial glial cell heterogeneity - the source of diverse progeny in the CNS. Prog Neurobiol 83:2-23.

Pow DV, Wright LL, Vaney DI (1995) The immunocytochemical detection of amino-acid neurotransmitters in paraformaldehyde-fixed tissues. J Neurosci Methods 56:115-123.

Ren J, Greer JJ (2003) Ontogeny of rhythmic motor patterns generated in the embryonic rat spinal cord. J Neurophysiol 89:1187-1195.

Roux MJ, Supplisson S (2000) Neuronal and glial glycine transporters have different stoichiometries. Neuron 25:373-383.

Shestopalov VI, Panchin Y (2008) Pannexins and gap junction protein diversity. Cell Mol Life Sci 65:376-394.

Spitzer NC (2006) Electrical activity in early neuronal development. Nature 444:707-712.

Suadicani SO, Brosnan CF, Scemes E (2006) P2X $\mathrm{X}_{7}$ receptors mediate ATP release and amplification of astrocytic intercellular $\mathrm{Ca}^{2+}$ signaling. J Neurosci 26:1378-1385.

Tabak J, Rinzel J, O’Donovan MJ (2001) The role of activity-dependent network depression in the expression and self-regulation of spontaneous activity in the developing spinal cord. J Neurosci 21:8966-8978.

Ternovsky VI, Okada Y, Sabirov RZ (2004) Sizing the pore of the volumesensitive anion channel by differential polymer partitioning. FEBS Lett 576:433-436.

Varela D, Simon F, Olivero P, Armisén R, Leiva-Salcedo E, Jørgensen F, Sala F, Stutzin A (2007) Activation of $\mathrm{H}_{2} \mathrm{O}_{2}$-induced VSOR Cl${ }^{-}$currents in HTC cells require phospholipase Cgammal phosphorylation and $\mathrm{Ca}^{2+}$ mobilisation. Cell Physiol Biochem 20:773-780.

Vígh B, Manzano e Silva MJ, Frank CL, Vincze C, Czirok SJ, Szabó A, Lukáts A, Szél A (2004) The system of cerebrospinal fluid-contacting neurons. Its supposed role in the nonsynaptic signal transmission of the brain. Histol Histopathol 19:607-628.

Weissman TA, Riquelme PA, Ivic L, Flint AC, Kriegstein AR (2004) Calcium waves propagate through radial glial cells and modulate proliferation in the developing neocortex. Neuron 43:647-661.

Young SH, Poo MM (1983) Spontaneous release of transmitter from growth cones of embryonic neurones. Nature 305:634-637.

Yvert B, Branchereau P, Meyrand P (2004) Multiple spontaneous rhythmic activity patterns generated by the embryonic mouse spinal cord occur within a specific developmental time window. J Neurophysiol 91:21012109.

Zhang LI, Poo MM (2001) Electrical activity and development of neural circuits. Nat Neurosci 4 [Suppl]:1207-1214. 